\title{
Feedforward and recurrent inhibitory receptive fields of principal cells in the cat's dorsal lateral geniculate nucleus
}

\author{
Sivert Lindström • Andrzej Wróbel
}

Received: 28 July 2010 /Revised: 13 October 2010 / Accepted: 3 November 2010 / Published online: 3 December 2010

(C) The Author(s) 2010. This article is published with open access at Springerlink.com

\begin{abstract}
Principal cells in the dorsal lateral geniculate nucleus receive both feedforward and recurrent inhibition. Despite many years of study, the receptive field structure of these inhibitory mechanisms has not been determined. Here, we have used intracellular recordings in vivo to differentiate between the two types of inhibition and map their respective receptive fields. The feedforward inhibition of a principal cell originates from the same type of retinal ganglion cells as its excitation, while the recurrent inhibition is provided by both on- and off-centre cells. Both inhibitory effects are strongest at the centre of the excitatory receptive field. The diameter of the feedforward inhibitory field is two times larger, and the recurrent two to four times larger than the excitatory field centre. The inhibitory circuitry is similar for $\mathrm{X}$ and $\mathrm{Y}$ principal cells.
\end{abstract}

Keywords Dorsal lateral geniculate nucleus · Postsynaptic inhibition $\cdot$ Receptive fields

Electronic supplementary material The online version of this article (doi:10.1007/s00424-010-0900-7) contains supplementary material, which is available to authorized users.

\section{S. Lindström}

Department of Clinical and Experimental Medicine,

University of Linköping,

S-581 85 Linköping, Sweden

\section{A. Wróbel $(\bowtie)$}

Department of Neurophysiology,

Nencki Institute of Experimental Biology,

3 L. Pasteur Street,

02-093 Warsaw, Poland

e-mail: a.wrobel@nencki.gov.pl

\section{Introduction}

Almost 50 years have passed since Hubel and Wiesel [27] described the receptive field structure of cells in the cat's dorsal lateral geniculate nucleus (dLGN). They found geniculate cells to have concentric receptive fields of onor off-centre type, just like retinal ganglion cells. The only obvious difference was an increased peripheral antagonism of the centre response, which they proposed to be due to local inhibition in the dLGN.

Shortly afterwards, postsynaptic inhibitory potentials were recorded in geniculate cells by several investigators [51]. Today, it is known that geniculate principal cells are equipped with two inhibitory circuits: a feedforward inhibitory system with the responsible interneurons located within the main layers of the dLGN and a recurrent inhibitory system with the interneurons confined to the perigeniculate nucleus $[18,32,48]$. Both types of inhibitory neurons have GABA as their main transmitter. The inhibitory circuits are similar but functionally segregated for $\mathrm{X}$ and $\mathrm{Y}$ cells [34]. Apparently, the dLGN is composed of a large number of interdigitated neuronal "processing units" formed by individual principal cells and their inhibitory circuits [6].

These dLGN processing units have been analysed with anatomical and electrical stimulation techniques. While such procedures are excellent to reveal the serial order of connections between cells they cannot be used to identify other functionally important aspects of the circuitry such as the spatial distribution and receptive field type of the involved neurons. Nor can they reveal whether the feedforward or the recurrent inhibitory pathway is responsible for a particular inhibitory effect in the principal cell response to visual stimulation. Many studies, primarily based on indirect techniques, have aimed to elucidate such functions [7, 48, 49, 51], and a variety of models for dLGN inhibition have been 
proposed, none of which has received general acceptance. The problem is clearly related to the difficulty to differentiate between true inhibition and disfacilitation, i.e. reduced excitation of the principal cells. It seems firmly established, however, that the enhanced antagonistic surround of dLGN neurons is due to GABAergic inhibition $[8,50]$.

Two recent studies have reiterated the described difficulties. In an elegant in vitro study in mice, Blitz and Regehr [10] convincingly demonstrated that many feedforward IPSPs in principal cells are time-locked to unitary excitatory postsynaptic potentials (EPSPs) from retinal ganglion cells. This coupling, observed also in the cat [34], implies that at least some feedforward inhibition is provided by the very same retinal ganglion cells as the excitation. The other study, focusing on principal cell responses to natural visual scenes, arrived at the contrary conclusion, namely, that the feedforward inhibition originates from the opposing type of retinal ganglion cell [63]. There is clearly a need to resolve this issue, especially since the two inhibitory systems appear to be independently controlled from the brain stem [2] and the basal forebrain [9]. Such connections open the possibility that the two types of inhibition and thus, the visual transfer through the dLGN, might be differentially regulated in various behavioral situations.

In an attempt to resolve the disagreement in this otherwise well-studied system, we have combined direct intracellular recordings of inhibitory postsynaptic potentials in dLGN principal cells with adequate visual stimulation. Our procedure with strong cell depolarisation allowed feedforward and recurrent IPSPs to be distinguished and the receptive field structure of the two inhibitory mechanisms to be analysed.

\section{Experimental procedures}

\section{Animal preparation}

Experiments were performed on 14 young adult cats (2.1$3.0 \mathrm{~kg}$ ). Anaesthesia was induced with an alphaxalonealphadolone mixture (Saffan, Glaxovet; $12 \mathrm{mg} / \mathrm{kg}$, i.m. followed by sodium pentobarbitone (Apoteksbolaget; 25$30 \mathrm{mg} / \mathrm{kg}$, i.v.). Additional small doses of pentobarbitone $(5 \mathrm{mg} / \mathrm{kg}$ ) were given to maintain an appropriate depth of anaesthesia during the surgical procedure and subsequent recording session. Heart rate and arterial blood pressure were continuously monitored. Mean arterial blood pressure was maintained above $120 \mathrm{~mm} \mathrm{Hg}$ by slow infusion of bicarbonate-buffered Ringer glucose. Body temperature was kept between 37.5 and $38.5^{\circ} \mathrm{C}$ by a feedbackcontrolled heating lamp. During intracellular recordings the animals were paralysed by gallamine triethiodide (Flaxedil, May and Baker) added to the infusate. Continuous ECoG recordings were used in this situation to ascertain that the animals remained in a state of slow wave sleep. They were artificially ventilated through a tracheotomy with a positive end-expiratory pressure of 1-2 cm $\mathrm{H}_{2} \mathrm{O}$. Tidal volume was adjusted to maintain end-expiratory $\mathrm{CO}_{2}$ at $3.5-3.7 \%$. To further reduce respiratory-linked movements of the brain, the animals were suspended by a stereotactic head holder and a clamp placed at a midthoracic vertebrae. A pneumothorax was also performed prior to the recordings. The corneas were covered with contact lenses with a curvature appropriate to focus them on a tangent screen $1.5 \mathrm{~m}$ in front of the cat. Pupils were fully dilated, accommodation paralysed, and nictitating membranes retracted by local application of $1 \%$ atropine and $10 \%$ neosynephrine. At the end of the experiment, animals were killed by an overdose of the anaesthetics. The experiments were approved by the Regional Animal Care and Use Committee in accordance with Swedish law.

\section{Intracellular recordings}

Intracellular recordings were obtained from dLGN principal cells with glass micropipettes filled with $3 \mathrm{M}$ sodium acetate. Such electrodes gave better intracellular recordings than conventional electrodes filled with potassium salts [34]. The microelectrodes had their tips broken back to a diameter of about $0.5 \mu \mathrm{m}$, giving a DC resistance of about $15-30 \mathrm{M} \Omega$.

To obtain maximal stability, only a small craniotomy $(2 \times 3 \mathrm{~mm})$ was made above dLGN. The microelectrode was then advanced through the overlying cortex down to the dLGN with a stepping motor micromanipulator. After the beginning of each track, the exposed cortex was covered by body-warm agar to further reduce pulsation. Principal cells were recognized in extracellular recordings by their position in the dLGN, by their receptive field properties and by antidromic activation from the visual cortex. When penetrated, the cells were rapidly hyperpolarised by a small negative current through the microelectrode in order to stabilise the recordings and to stop the injury discharge.

Only cells with reasonably stable recordings lasting for more than half an hour could be used for this study. In order to analyse inhibitory and excitatory potentials in isolation, it was necessary to polarise the cells by large current injections through the recording electrode (see "Results"). This was a brutal procedure and most cells eventually deteriorated. Since the current injections usually caused electrode polarisation and drifts in recorded DC potentials, it was, for most cells, impossible to deduce the actual membrane potentials during different phases of the analysis. Only a handful of cells remained stable, as far as we could judge, during the entire recording session (more than $2 \mathrm{~h}$ ). When stepping out of these cells, DC potential changes in the $60-75 \mathrm{mV}$ range were recorded. Since we intentionally tried to inactivate the spike mechanism by strong depolar- 
isation, spike amplitudes could neither be used to monitor cell quality. As an alternative, we used the amplitude of unitary EPSPs evoked by optic nerve stimulation to monitor the stability of the recordings.

\section{Stimulation procedures}

The connectivity of principal cells were characterised both by electrical and adequate visual stimulation. Stimulation electrodes were placed at three sites along the visual pathway: around the optic nerves just behind the eye bulbs $(\mathrm{ON})$, in the optic tract $(\mathrm{OT})$ and in the visual cortex $(\mathrm{Cx}$; Fig. 1, diagram). Graded electrical stimulation (constant current stimulator, $0.2 \mathrm{~ms}$ pulses) of the optic nerves were used to obtain separate activation of Y- and X-type ganglion cell axons [34] and to evoke monosynaptic EPSPs and feedforward IPSPs in the principal cells. The cortex electrodes were used for antidromic activation of the cells and to evoke recurrent IPSP.

Receptive fields were plotted against a mesopic background. Their location and approximate size were first

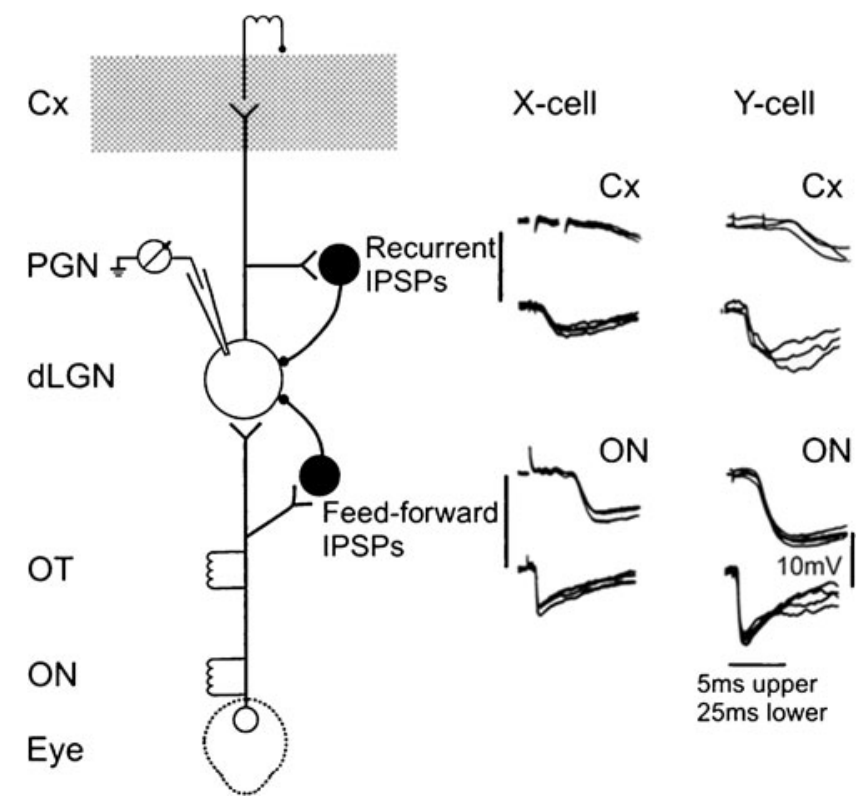

Fig. 1 Schematic diagram of experimental arrangement and inhibitory pathways of the dLGN. Intracellular recordings of IPSPs obtained from an $\mathrm{X}$ on-centre and a Y off-centre principal cell. Upper pairs of records show superimposed traces with recurrent IPSPs evoked by antidromic activation of principal cell axons in the visual cortex $(C x)$ at an intensity subthreshold for activation of corticogeniculate axons, lower pairs feedforward IPSPs evoked by optic nerve stimulation $(\mathrm{ON})$. The two records in a pair show the same response displayed with different time resolution. Note difference in time course of recurrent and feedforward IPSPs and longer latency of the responses in the $\mathrm{X}$ cell. The $\mathrm{X}$ and $\mathrm{Y}$ cells were depolarised by a steady injection of current (4 and $5 \mathrm{nA}$ ) through the recording microelectrode. Voltage calibration refers to all records, time calibration is $5 \mathrm{~ms}$ for upper record in each pair and $25 \mathrm{~ms}$ for lower. $P G N$ Perigeniculate nucleus, $d L G N$ dorsal lateral geniculate nucleus, $O T$ optic tract determined with extracellular recordings. To classify cells as $\mathrm{X}$ or $\mathrm{Y}$ types, we primarily relied on spatial resolution tests: receptive field centre size in relation to eccentricity and/or spatial resolution as tested with moving gratings of different spatial frequencies $[13,57]$. There was sufficiently good correlation between these measures and cell classification based on thresholds and latencies with optic nerve stimulation to render more sophisticated visual classification schemes obsolete [34]. To establish the eccentricity, the area centralis and optic disk position were mapped for each cell. The expected progression of receptive field positions with electrode advancement through the dLGN and the changes of ocular preference at laminar borders made histological confirmations unnecessary.

Once the cells were penetrated, their excitatory receptive fields were remapped by the recording of visually evoked unitary EPSPs. The cells were then depolarised to reveal unitary feedforward IPSPs and recurrent IPSPs. The size and contrast of the small light spots were adjusted individually for each cell to give a reproducible but weak response with resolvable unitary PSPs. Typical test spots were $0.3-0.6$ times the diameter of the excitatory receptive field centre. These adjustments were necessary to allow the differentiation of feedforward and recurrent IPSPs. Thus, most stimuli were suboptimal with respect to response latency and amplitude, implying that data from different cells could only be compared qualitatively. The shutter of the projector was controlled by the stimulator, and consecutive points within the receptive fields were adjusted manually and marked on the screen.

The visual stimuli were delivered at a repetition rate of $0.5 \mathrm{~Hz}$ and lasted 0.5 or $1.0 \mathrm{~s}$. The evoked responses were appropriately amplified and stored for offline analysis. Due to background synaptic noise, it was impossible to use automatic detection procedures, each response had to be inspected by eye at large amplification and expanded time resolution in order to identify evoked unitary PSPs. To compensate for the variability in visually evoked responses, each stimulus configuration was repeated five to ten times so that consistent components could be identified. To quantify feedforward inhibitory effects, we counted unitary EPSPs and IPSPs, scaled with an appropriate size factor (comp. the middle column of Fig. 8), during a predetermined time interval (typically including the time of phasic part of responses, approximately $100 \mathrm{~ms}$ ). Quantitative data from many stimulus trials were than normalised with respect to the largest response and plotted as weighted means $\pm 95 \%$ confidence intervals (CI). For some cells, the responses were averaged offline, once individual feedforward IPSPs had been identified. Recurrent inhibitory effects were also estimated by offline averaging, after subtracting identifiable feedforward IPSPs (comp. supplementary Fig. S3). The recurrent IPSP were quantified by integrating 
the IPSP area in averages of 5-10 repetitions using a straight horizontal baseline and own software (e.g. Fig. 9, position 6).

\section{Results}

The present report is based on intracellular recordings from 51 functionally identified principal cells $(25 \mathrm{X}$ and $26 \mathrm{Y}$ types). Half the sample consisted of on-centre cells (14 X, $12 \mathrm{Y}$ ), the rest were off-centre cells (11 X, $14 \mathrm{Y})$. Six X cells had antidromic latencies (for cortical stimulation) above $2.2 \mathrm{~ms}$ and slow responses to visual stimulation, indicating that they belonged to the lagged X cell category [39]. Such cells are known to be among the smallest X cells [28]. They did not differ in any other respect from the rest of the $\mathrm{X}$ cell sample, but including them made us to believe that we have studied a representative sample of $\mathrm{X}$ and $\mathrm{Y}$ principal cells. A summary of various cell parameters is provided in the supplement (Fig. S1).

\section{Identification of feedforward and recurrent IPSPs}

Our goal for this study required means to differentiate between feedforward and recurrent IPSPs during visual stimulation. These IPSPs differ considerably in time course, when evoked by electrical stimulation [32, 34]. Feedforward IPSPs have much shorter rise and decay times than recurrent IPSPs, both in X and Y cells (Fig. 1), and it seemed possible to utilise these characteristics also when analysing visually evoked responses.

The difference in IPSP time course is explained by a much stronger synaptic coupling in the feedforward than in the recurrent inhibitory pathway. Intrageniculate interneurons that mediate the feedforward inhibition receive large unitary EPSPs from a small number of retinal ganglion cells and fire impulses time-locked to such EPSPs [1, 33, 41]. The subsequent IPSPs evoked in principal cells are also large [1] and time-locked to spikes in the responsible optic nerve fiber, whether evoked by electrical or visual stimuli.

The recurrent system differs in all these aspects. Axon collaterals from many principal cells converge onto the same perigeniculate cell with small unitary EPSPs [3, Lindström and Wróbel, unpublished observations]. Their unitary IPSPs in principal cells are also small, compared to the feedforward IPSPs, and difficult to resolve individually [32]. Compound IPSPs, as in Fig. 1, are formed by temporal summation of a large number of asynchronous unitary events, which explains their slow rise and decay time course. We expected the IPSPs to be even slower with asynchronous excitation of the perigeniculate cells from many principal cells during visual stimulation.
Note that the recurrent IPSPs in Fig. 1 were evoked at a stimulation intensity subthreshold for activation of corticogeniculate axons as revealed by the lack of fast IPSPs from intrageniculate interneurones superimposed on the slow recurrent IPSPs and by the lack of corticogeniculate EPSPs in the principal cells (not shown $[6,33,35]$ ).

\section{Feedforward IPSPs}

Typical feedforward IPSPs evoked in an X on-centre cell by electrical stimulation (A), spontaneous activity (B) and visual stimulation (C) are shown in Fig. 2. In order to amplify EPSPs and IPSPS at the expense of each other, the cell was polarised by current injection through the recording electrode. The lower pairs of traces were obtained with the cell hyperpolarised towards the IPSP reversal level and show EPSPs with little contamination from IPSPs. This cell received excitation from a single retinal ganglion cell as revealed by the response evoked at threshold intensity (left pair of records) and by the spontaneous activity. The visual response starts by summation of two large EPSPs in rapid
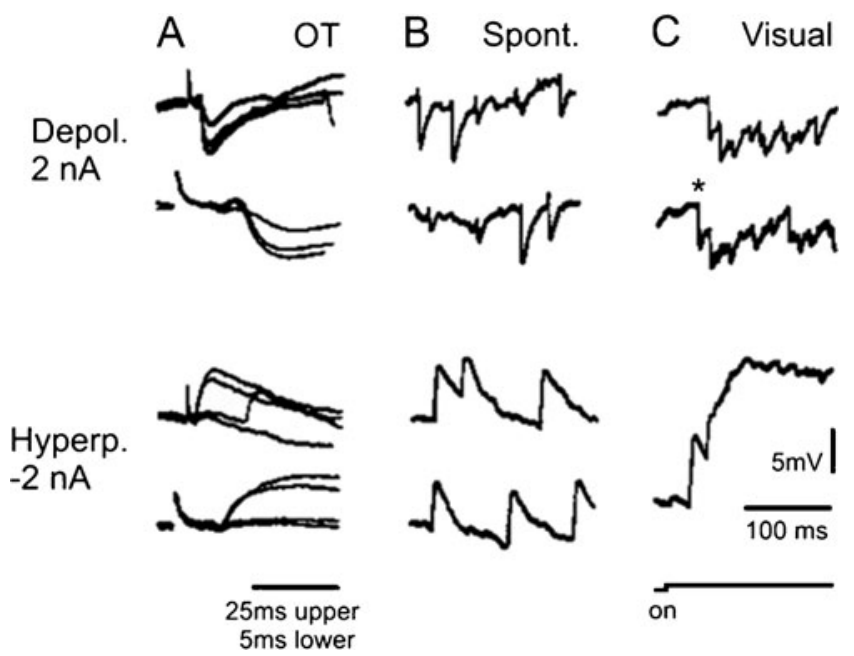

Fig. 2 Identification of feedforward IPSPs in an X on-centre principal cell. Records in column A show monosynaptic EPSPs and disynaptic feedforward IPSPs evoked by optic tract $(O T)$ stimulation, each pair is the same response displayed at different time resolution. Sample records in $\mathbf{B}$ show spontaneous activity and those in $\mathbf{C}$ responses evoked by flashing a light spot on in the receptive field centre. Upper pairs of records were obtained with the cell depolarised ( $2 \mathrm{nA})$, lower pairs during hyperpolarisation $(2 \mathrm{nA})$. The cell was activated by a single retinal ganglion cell. Note fast IPSPs of feedforward type in all responses during depolarization. Most feedforward IPSPs were timelocked to a preceding EPSP (decreased by the depolarisation) at a fixed interval of $0.8 \mathrm{~ms}$. They varied in several discrete steps in amplitude. The second visual response started with a large nonlocked feedforward IPSP (asterisk), another smaller occurred after an EPSP failure with electrical stimulation. Time calibration in $\mathbf{A}$ is $25 \mathrm{~ms}$ for upper and $5 \mathrm{~ms}$ for lower traces in the pair. Time calibration lowermost in $\mathbf{C}$ refers to records in $\mathbf{B}$ and $\mathbf{C}$, voltage calibration to all records. See text for further details 
succession followed by a slow depolarisation presumably representing a calcium response [30].

With depolarising current injections (upper pairs of traces), the optic nerve stimulation evoked a combined EPSP-IPSP response (A). The IPSP had a disynaptic latency indicating that it was mediated by the feedforward pathway [34]. Similar PSP combinations were seen in the records with spontaneous activity (B) with the EPSP indicated by a small upwards deflection followed by an IPSP. Visual stimulation of the receptive field centre (C) evoked a burst of IPSPs that were also similar in size and time course as the feedforward IPSPs evoked by electrical stimulation.

Note that practically all PSPs were of the combined type with the IPSP time-locked to a small positive deflection, representing a preceding EPSP. There was a fixed latency difference of $0.8 \mathrm{~ms}$, between the two PSP components, whether evoked by electrical stimulation, visual stimulation or during spontaneous activity. The interval was also the same after reversal of the IPSP by the injection of a strong hyperpolarising current (not illustrated, see Ref. [31]). This latency difference proves that the biphasic responses were combined EPSPs-IPSPs and not partially reversed EPSPs. The tight temporal coupling of the two responses demonstrates that they were triggered by single spikes from the same excitatory retinal ganglion cell [10, 34].

Combined EPSPs-IPSPs were found in the large majority of the recorded cells (46/51), especially during visual stimulation. For the receptive field analysis, we usually depolarised the cells, so that biphasic PSP could be resolved, rather than to the EPSP reversal level. In the following, feedforward IPSPs time-locked to EPSPs will be referred to as "locked IPSPs," while those without preceding EPSPs will be called "nonlocked IPSPs" (following the suggestion by Blitz and Regehr [10]). The lower response to visual stimulation starts by a large nonlocked feedforward IPSP (asterisk, Fig. 2c, second response). A smaller nonlocked IPSP occurred after an EPSP failure in the response to OT stimulation (Fig. 2a). Note that both types of IPSPs could vary considerably in amplitude. Measurements from a long sequence of recordings from the illustrated cell showed feedforward IPSPs of at least four amplitudes and occasional EPSPs without an IPSP. The stepwise change in IPSP amplitude is explained by the convergence of several feedforward inhibitory interneurons onto the same principal cell [34], with the interneurons being influenced by the same retinal ganglion cell(s). A variation in the firing probability of these interneurons would give IPSPs of different amplitudes coupled to the EPSPs. Interestingly, the maximal IPSP that occurred spontaneously or after visual stimulation had in this and several other cells the same amplitude as the maximal feedforward IPSP evoked by electrical stimulation of the optic nerve.

\section{Recurrent IPSPs}

Slow hyperpolarisations that could qualify as recurrent IPSPs frequently occurred both spontaneously during sleep spindles in the ECoG [42] and in response to visual stimulation. In the latter case, they were most easily observed with stimuli that stopped ongoing EPSP activity in the studied principal cell, e.g. central on stimuli for an off-centre cell (Fig. 3a). Current injections were regularly used to determine if such hyperpolarisation were true IPSPs and not simply due to disfacilitation, i.e. decreased excitation from retinal ganglion cells or cortico-geniculate neurons in layer 6 of the visual cortex [35]. Reduced activity in the latter feedback system would appear as a rather smooth hyperpolarisation of the principal cell since many recurrent excitatory neurons converge onto individual principal cells with small unitary EPSPs [23, 35]. Other excitatory inputs to perigeniculate and intrageniculate interneurones, such as excitation via the corticogeniculate feedback system, would evoke the same two types of IPSPs as characterised above. We think this feedback mechanism made little contribution to our visually evoked responses (see "Discussion"), especially since fast IPSPs of the feedforward type were not typically superimposed on the slow IPSP in the opposing mode of stimulation (light on mode in Fig. 3a).

In the illustrated case (Fig. 3a), the slow stimulus evoked hyperpolarisation increased in amplitude with depolarisation and reversed polarity with the hyperpolarising current, as expected for a true IPSP. A similar late slow IPSP component was hidden by the fast feedforward IPSPs in the light off mode of stimulation (Fig. 3b, d). Since perigeniculate neurons receive convergent excitation, via axon collaterals of both on- and off-centre principal cells, it is not a farfetched conclusion that both these slow IPSPs were of the recurrent type (although we cannot exclude some contribution from calcium spikes in intrageniculate interneurons in the off mode; [1]). Note in the diagrams (Fig. 3d, e) that the recurrent IPSP at light on had about the same reversal level as the feedforward IPSP evoked in the same cell by optic tract stimulation (displayed at higher time resolution in Fig. 3c). This correspondence would be expected if both IPSPs involved GABA-A regulated $\mathrm{Cl}^{-}$ channels. We did not observed slow IPSPs with more negative reversal levels that could qualify as GABA-B mediated effects, connected to $\mathrm{K}^{+}$channels.

\section{Basic pattern of feedforward inhibition}

Using the described criteria to identify feedforward IPSPs we tried to evoke such IPSPs by visual stimuli placed in different parts of the receptive field of the principal cells. Our main findings are described in Fig. 4 with recordings from an $\mathrm{X}$ 


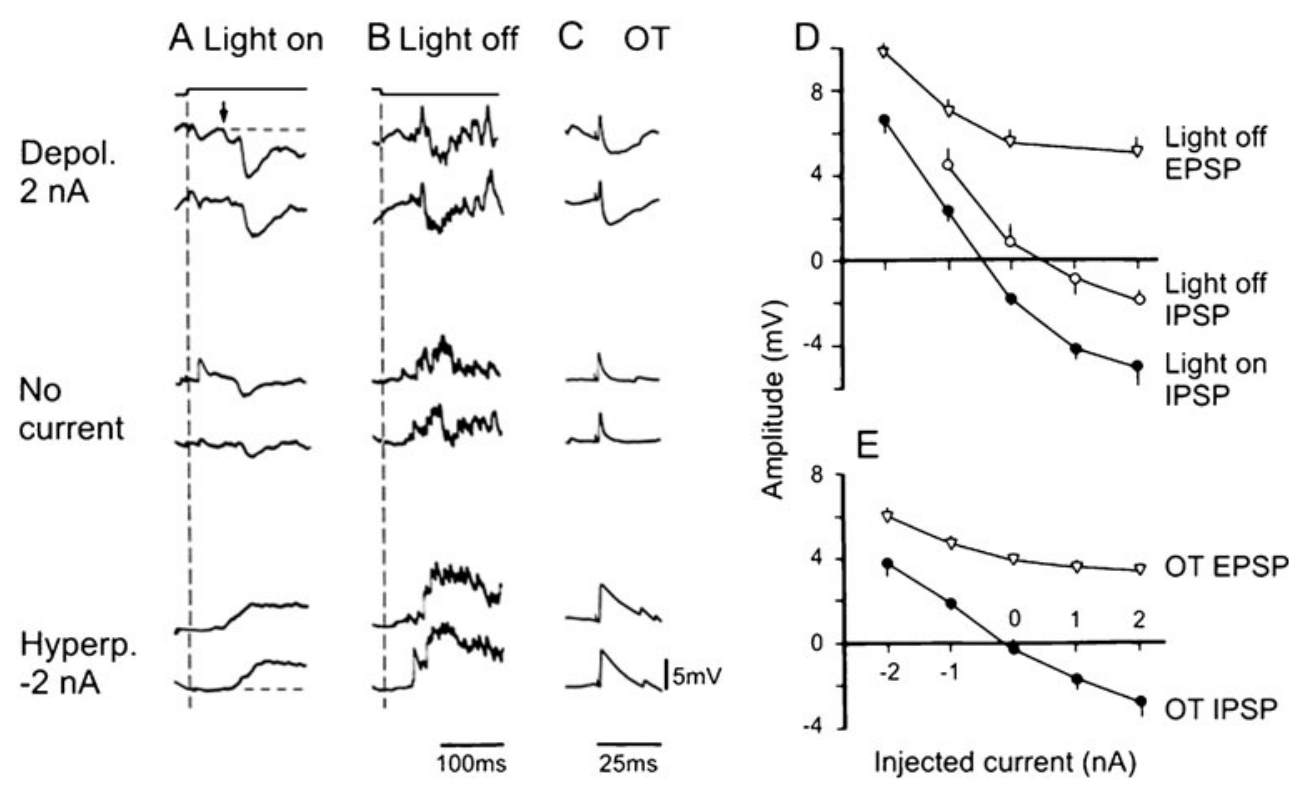

Fig. 3 Identification of visually evoked recurrent IPSPs in an X offcentre principal cell. A and B show responses evoked by a light spot turned on and off in the receptive field centre, records in $\mathbf{C}$ are PSPs evoked by electrical stimulation of the optic tract (OT). The cell was depolarised and hyperpolarised as indicated to enhance or reverse the recurrent IPSP (upper and lower pair of records in A). Onset of the recurrent IPSP is marked by an arrow in $\mathbf{A}$. Voltage calibration in $\mathbf{C}$ refers to all records, time calibration in $\mathbf{B}$ is for records in $\mathbf{A}$ and $\mathbf{B}$. Diagram in $\mathbf{D}$ shows voltage dependence of visually evoked synaptic potentials (means of many records as in $\mathbf{A}$ and $\mathbf{B}$ ) plotted against

off-centre cell with dominant excitation from a single retinal ganglion cell. At light off, a small centre spot produced a burst of EPSPs that summed to a tonic excitation with superimposed spikes (Fig. 4a). When the cell was sufficiently depolarised to block all spikes, it was obvious that these EPSPs were associated with large, fast IPSPs (Fig. 4b). Most of these IPSPs were of the EPSP-locked type discussed above (Fig. 4c, upper time expanded trace). The locked IPSPs varied in amplitude but had similar time course as the feedforward IPSP evoked in the same cell by electrical stimulation of the optic nerve (Fig. 4c, lowermost trace). Thus, there can be little doubt that these IPSPs were mediated by the feedforward inhibitory system. At light on the EPSP activity ceased and no stimulus driven feedforward IPSPs could be seen (Fig. 4d, upper trace).

An enlarged spot covering most of the excitatory receptive field centre produced stronger inhibition with shorter latency at light off (spot 2). A close inspection at larger amplification revealed that also this inhibitory response was evoked by temporally summating fast IPSPs of feedforward type (not illustrated). Only about a fifth of the fast IPSPs were nonlocked as judged by many similar stimulation sequences. At light on, there was a late, slow hyperpolarisation but no fast IPSPs. This late hyperpolarisation was a recurrent IPSP, which will be described later. injected current. Vertical bars represent the 95\% CI. Light on and off IPSP values represent peak amplitudes taken at a latency of 90 $100 \mathrm{~ms}$ after stimulus onset, light off EPSP represents peak EPSP amplitudes at $60-70 \mathrm{~ms}$ interval after stimulus off. Diagram in $\mathbf{E}$ shows voltage dependence of monosynaptic EPSPs and disynaptic IPSPs evoked by OT stimulation. IPSPs were measured at an interval corresponding to its peak amplitude in depolarised recordings without EPSP subtraction. Note that visually evoked recurrent IPSPs reversed at about the same level of polarisation as feedforward IPSPs

A small spot in the receptive field periphery (Spot 3) was completely ineffective both at light off and on. With an annulus, only a slow hyperpolarisation was evoked at light off. The single fast IPSP occurring after about $60 \mathrm{~ms}$ was due to ongoing spontaneous activity and was not seen in other records. At annulus on there was a late burst of EPSPs representing the surround response of the excitatory retinal ganglion cell. As with the centre response, there were feedforward IPSPs locked to these EPSPs.

For simplicity, each stimulus type is only illustrated by single representative records in Fig. 4. Due to the spontaneous activity of retinal ganglion cells such traces contain much synaptic noise. To identify stimulus dependent activity it was always necessary to study many individual responses at high resolution. The reproducibility of the responses in this cell can be judged from more single traces displayed in Fig. 8.

It should be clear from the records in Figs. 2 and 4 that feedforward IPSPs were evoked at the same phase of stimulation as the EPSPs, i.e. the inhibitory input to the cell originated from the same kind of retinal ganglion cells as its excitation. Since most centre-evoked IPSPs were EPSPlocked, it is also evident that the excitatory retinal ganglion cell was among the drivers of the feedforward inhibitory interneurons. The same pattern of feedforward inhibition 

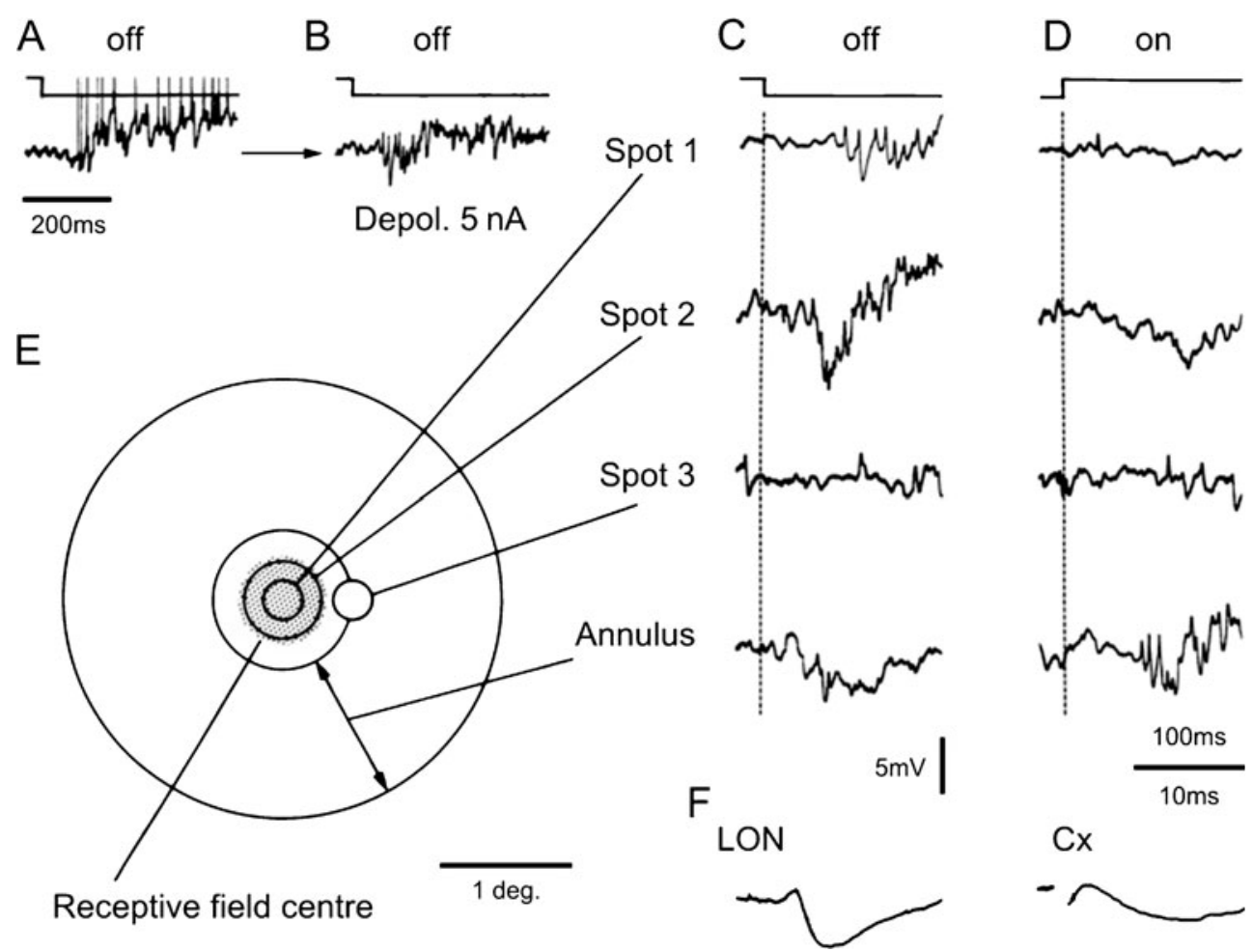

Fig. 4 Visually evoked feedforward IPSPs in an X off-centre principal cell. A Excitatory response evoked at resting membrane potential level by turning a light spot 1 off in the receptive field centre (action potentials truncated). B Response evoked with the cell depolarised by steady current injection ( $5 \mathrm{nA})$. C, D Light off and on responses evoked from different parts of the receptive field as indicated, cell depolarised as in $\mathbf{B}$. E Scheme of the receptive field and

from the receptive field centre was found for all 51 studied principal cells, $\mathrm{X}$ and $\mathrm{Y}$ cells of both on- and off-centre types, including six lagged $\mathrm{X}$ cells. Sample responses for each cell type, recorded with the cells strongly depolarised, are illustrated in Fig. 5. For each cell, the test spot had a diameter of less than half the excitatory receptive field centre. It is easy to see that feedforward IPSPs were evoked at light on in the centre of on-centre cells and at light off in off-centre cells. There was no evidence of feedforward IPSPs in the opposite phase of stimulation, only late, slow IPSPs of recurrent type. The feedforward inhibitory responses were very similar in $\mathrm{X}$ and $\mathrm{Y}$ cells with the exception that, after an initial transient component, the inhibitory activity was more tonic in $\mathrm{X}$ cells than in $\mathrm{Y}$ cells. In no cell did we find evidence for feedforward inhibition from retinal ganglion cells of the opposite type to those providing centre excitation of the principal cell.

For $\mathrm{X}$ cells, the situation was straightforward and simple: with the opposite phase of centre stimuli, the IPSP activity ceased together with that of the EPSPs (Fig. 5a, b). With extracellular recordings, there is a pause in the spike activity of principal cells in this phase. Clearly, this pause is primarily due to lack of excitation (disfacilitation), caused outlines of the visual stimuli. The area of the receptive field centre is dotted. F Feedforward and recurrent IPSPs evoked by electrical stimulation of the left optic nerve $(L O N)$ and visual cortex $(C x)$. Voltage calibration is for all records, time calibration in $\mathbf{A}$ is for $\mathbf{A}$ and $\mathbf{B}$, that lowermost in $\mathbf{D}$ is $100 \mathrm{~ms}$ for $\mathbf{C}$ and $\mathbf{D}$ and $10 \mathrm{~ms}$ for $\mathrm{ON}$ and Cx evoked IPSPs. See text for further details

by arrested activity in the input retinal ganglion cell(s) and not by active inhibition. The same is true for the pause in principal cell firing, caused by an opposing annulus in the periphery. Feedforward IPSPs could neither be seen in this phase. From the surround of X principal cells, feedforward IPSPs only occurred together with long-latency EPSPs resulting from surround activation of the input ganglion cell (s). It should be stressed that our visual stimuli were strong enough to activate neighbouring principal cells of on and off-centre types in each preparation. So our failure to detect opposing feedforward IPSPs cannot be due to inadequate visual stimulation. In many $\mathrm{X}$ cells, the largest unitary IPSPs were similar in amplitude to the maximal feedforward IPSPs evoked by electrical stimulation. so at least for these cells, there was no further feedforward inhibition to be accounted for.

For Y principal cells, the analysis was more complicated. They were "noisier" than X cells, due to excitatory convergence from several retinal ganglion cells. Their input ganglion cells also gave phasic on-off discharges to spot stimuli placed in an overlap zone between the centre and the surround. These overlap zones were spatially displaced for the different converging ganglion cells, resulting in on-off EPSPs from a 


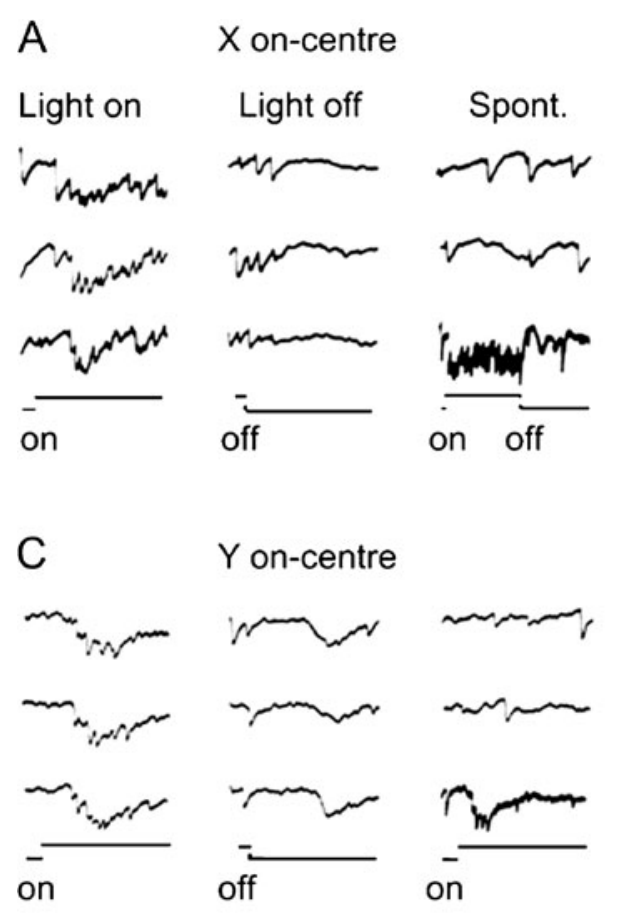

Fig. 5 Pattern of feedforward IPSPs in different types of principal cells. First two columns in A-D show three consecutive light on and off responses to a small spot in the receptive field centre; upper two responses in third columns show spontaneous activity and lowest trace a centre response at low time resolution. Note that feedforward IPSPs were evoked at light on in on-centre cells and at light off in off-centre cells, similarly for $\mathrm{X}$ and $\mathrm{Y}$ cells. Slow hyperpolarising potentials in

large portion of the principal cell receptive field. Usually, the Y principal cells also had large recurrent IPSPs of short latency. Such difficulties made it complicated to illustrate the selectivity of connections to such cells. However, after viewing many stimulus response sequences for each cell we became convinced that no Y cell had a significant feedforward inhibitory input from ganglion cells of the opposite type to those providing centre excitation. No unlocked IPSPs of feedforward type were evoked by opposing visual stimuli in their receptive field centre - only occasional spontaneous IPSPs at a low rate (cf. traces with spontaneous activity, Fig. 5c, d). From the surround region, IPSPs of feedforward type only occurred in association with excitatory surround responses from driving retinal ganglion cells. As expected, these surround responses invariably had a longer latency than the centre response. Thus, it is concluded that also $\mathrm{Y}$ cells lack feedforward inhibition from the opposite type of retinal ganglion cells.

Feedforward inhibitory receptive fields

The spatial structure of the feedforward inhibitory receptive field was determined quantitatively in 16 principal cells (ten

\section{B X off-centre}
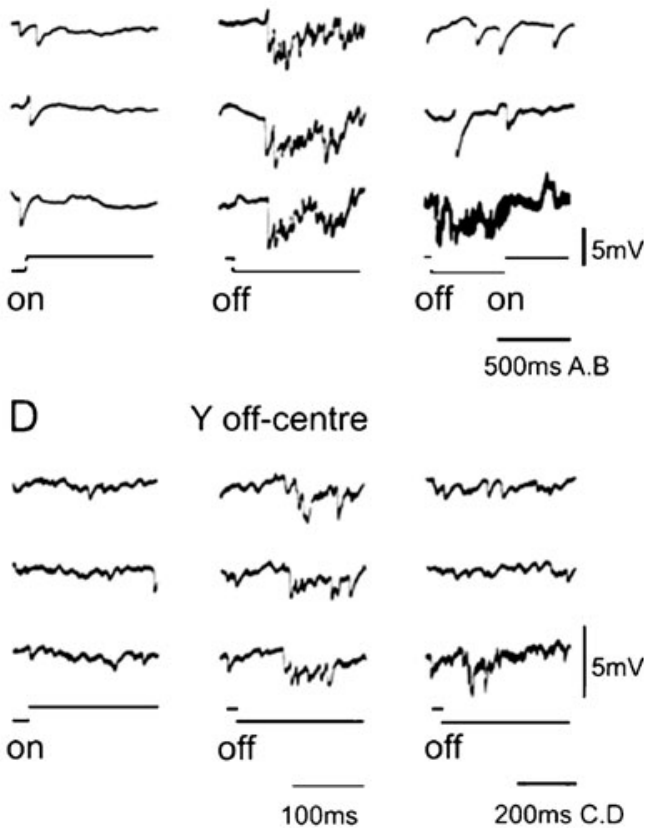

the opposite phase of stimulation are recurrent IPSPs. The cells were depolarised by the injection of steady current (2-3 nA). Voltage calibration for records in $\mathbf{A}$ and $\mathbf{B}$ is in $\mathbf{B}$, that for $\mathbf{C}$ and $\mathbf{D}$ in $\mathbf{D}$. Time calibrations for records in first columns and for spontaneous activity is below second column in $\mathbf{D}$, that for slow recordings below third columns in $\mathbf{B}$ and $\mathbf{D}$

$\mathrm{X}$ and six $\mathrm{Y}$ cells, half of each category were on-centre and half off-centre cells, four $\mathrm{X}$ cells were lagged). Two measurements were obtained, a receptive field profile determined by small test light spots placed in different positions along one or two axis through the excitatory receptive field centre and an area-response function with centred spots of different diameters.

\section{Feedforward receptive field profiles}

A typical receptive field profile for an $\mathrm{X}$ on-centre principal cell is illustrated in Fig. 6. The diagram shows the relative strength and spatial relation of the excitatory and inhibitory feedforward input to the cell based on PSP counts (see legends for details). This particular cell (same as in Fig. 2) received a large unitary EPSP from a single retinal ganglion cell and feed-forward IPSPs that varied in four discrete steps. Accordingly, identified IPSPs were multiplied by an appropriate size factor to obtain the weighted summed response. From the diagram, it is clear that the excitatory and inhibitory fields were centred at the same point and had about the same bell-shaped form. The diameter of the feedforward inhibitory receptive field was 

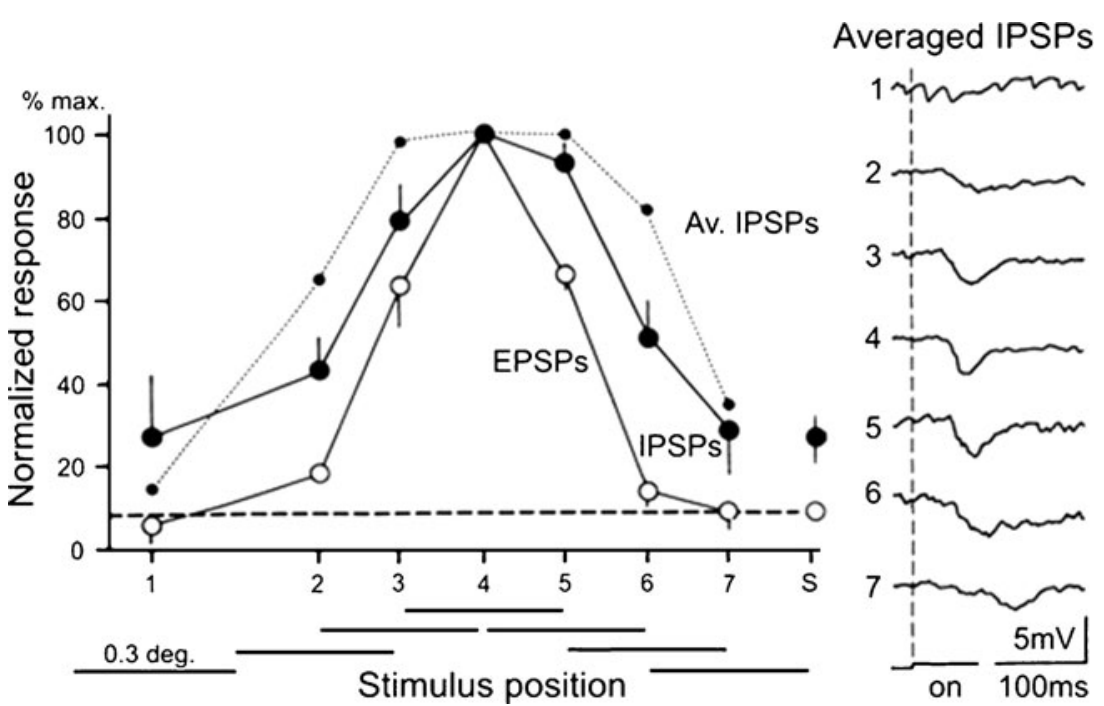

Fig. 6 Feedforward inhibitory receptive field profile for an $\mathrm{X}$ oncentre principal cell. The diagram shows the relative strength of the excitatory and feedforward inhibitory input to the cell from different positions along an axis through the centre of the receptive field. The size and position of the stimuli are indicated below the diagram. The cell was activated from the ipsilateral eye (lamina A1) and the eccentricity of its receptive field was $7^{\circ}$. The data were obtained by counting all unitary EPSPs and feedforward IPSPs during the first $100 \mathrm{~ms}$ after stimulus onset in a number of individual records for each position. The mean values were then normalised and plotted as percentage of the maximal response for each PSP (22.0 and 23.7/ $100 \mathrm{~ms}$ for EPSPs and IPSPs). Vertical bars represent 95\% CI. The cell had one large unitary EPSP and both locked and unlocked IPSPs

slightly larger, however. Measured at $1 / e$ of the peak response the inhibitory field was $0.9^{\circ}$ as compared to $0.5^{\circ}$ for the excitatory.

As an independent measure we averaged the feedforward IPSPs and integrated the area of the inhibitory response (Fig. 6, right column). Note that the slow rise of the IPSPs in these traces is due to smoothing by the averaging procedure. The measurements were restricted to the first $70 \mathrm{~ms}$ after stimulus on, since recurrent IPSPs contributed at longer intervals. With this method the size of the inhibitory response is somewhat underestimated for the receptive field centre due to interaction with EPSP currents. This interaction explains why the resulting inhibitory profile (Fig. 6, dotted line) is shallower than that based on IPSP counts. Even so, the width of the inhibitory field at 1/ $e$ was about the same. Similar profiles were found along the orthogonal axis of the receptive field with $1 / e$ diameters of $0.5^{\circ}$ for the EPSP and $0.8^{\circ}$ for the feedforward IPSP field (not illustrated).

A receptive field profile for a $\mathrm{Y}$ on-centre principal cell is shown in Fig. 7. This cell received excitation from three different neighbouring retinal ganglion cells giving unitary EPSPs of different amplitudes. Accordingly, the EPSP counts were also multiplied by a size factor to obtain a measure of the summed excitation. The diameter of the which varied in amplitude in several steps. They were divided into four size categories and each count was then multiplied with the appropriate size factor to obtain weighted means $( \pm 95 \% \mathrm{CI})$. The spontaneous rate of PSPs is indicated to the right $(S)$. The small points indicate the relative size of averaged feedforward IPSPs from the same stimulus positions, as illustrated by the sample records to the right. The area of the IPSPs was integrated, normalised, and plotted as for the unitary counts. Only the first $70 \mathrm{~ms}$ after stimulus on was used since the response at longer intervals was heavily contaminated by recurrent IPSPs. Note that the fast rise times of feedforward IPSPs is smoothed by the averaging. The cell was depolarised by a steady current injection $(2 \mathrm{nA})$ during the data collection. Same cell as in Fig. 2

excitatory centre at $1 / e$ of the peak response was $3.7^{\circ}$. Also for this cell, the feedforward inhibition was maximal at the EPSP receptive field centre. The diameter of the feedforward inhibitory profile, based on unitary counts, was $7.6^{\circ}$ at $1 / e$ of the peak response, i.e. twice that of the excitatory centre.

The organisation of the feedforward inhibitory field was similar in all the other tested principal cells with the peak of inhibition centred at the excitatory field centre. Further, the estimated inhibitory field diameter was not more than twice that of the EPSP field. For the total sample, the ratio of IPSP/EPSP field diameters ranged from 1.0 to 2.1 with no obvious difference between $\mathrm{X}$ and $\mathrm{Y}$ principal cells of either on- or off-centre type.

\section{Feedforward area-response functions}

We were intrigued by the findings that the feedforward inhibitory effect was strongest from the receptive field centre and that the effect decayed so rapidly at positions outside the excitatory centre. It was intuitively difficult to understand that an inhibitory system organised in this way could provide the enhanced antagonistic surround, as described by Hubel and Wiesel [27]. One possible explanation could be that the inhibitory input from 
peripheral regions required more spatial summation and was underestimated by our small test spots. For this reason we investigated area-response functions for feedforward IPSPs in $12 \mathrm{X}$ (six on-centre and six off-centre) and $11 \mathrm{Y}$ (eight on- and three off-centre) neurons. Three $\mathrm{X}$ and three $\mathrm{Y}$ cells were recorded sufficiently long to determine arearesponse curves with full range of spot diameters with representation of both on- and off-centre types.

The diagram in Fig. 8 was obtained from the same X offcentre cell as in Fig. 4 with the excitatory input dominated by a large EPSP from a single retinal ganglion cell. Such EPSPs were typically followed by locked feedforward IPSPs as shown by the sample traces to the right. At least six discrete amplitudes of locked and nonlocked IPSPs could be recognised (superimposed traces in the middle). To quantify the IPSP contribution during visual stimulation, we simplified the measurements by dividing the IPSPs into three size categories, multiplying each IPSP count with the relevant size factor. The mean count of unitary EPSPs and weighted IPSPs was then estimated from ten response trials, normalised and plotted against the spot size.

From the diagram, it can be seen that the highest EPSP count was obtained with a spot size of $0.6^{\circ}$. This stimulus covered the entire receptive field centre, as determined by the initial recording of extracellular spike activity. The EPSP count decreased with larger spot diameters covering more and more of the receptive field surround of the input retinal ganglion cell. The feedforward inhibition was strongest with a spot diameter twice as large $\left(1.2^{\circ}\right)$ as that for optimal excitation. With larger stimuli also the

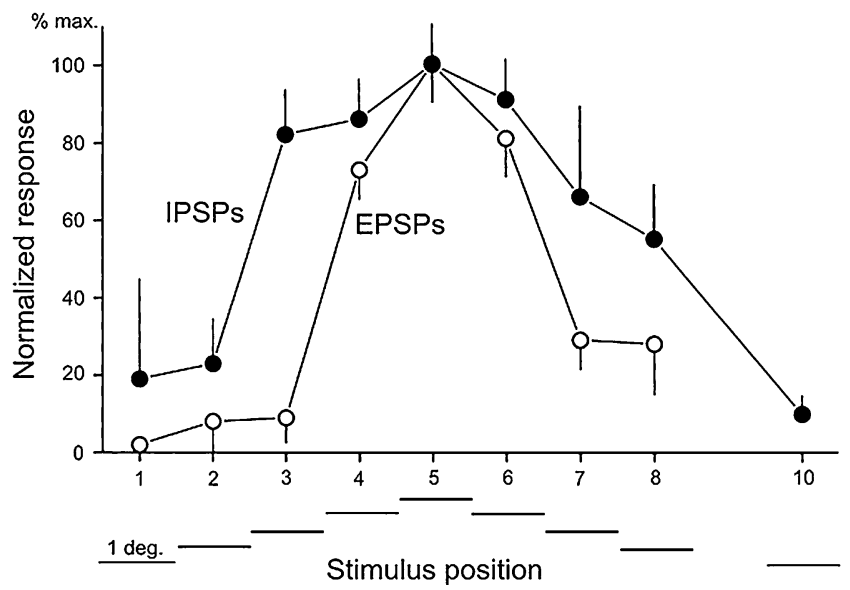

Fig. 7 Feedforward inhibitory receptive field profile for a Y on-centre principal cell. The PSPs were estimated and plotted as for Fig. 6. The cell received convergence of excitation from three $\mathrm{Y}$ on-centre ganglion cells in the contralateral eye; eccentricity was $11^{\circ}$. Both EPSPs and IPSPs were multiplied by an appropriate size factor before counting. The peak counts from the receptive field centre were 20/ $100 \mathrm{~ms}$ for both PSPs. Before normalisation, the spontaneous rate of PSPs (1.7 and 4.6/100 ms for EPSPs and IPSPs) was subtracted. See text for further details inhibition decreased with a similar slope as for the excitation.

The larger summation area for the feedforward inhibition seemed sufficient to account for the enhanced surround inhibition of this principal cell. This fact is best appreciated if we compare the responses to a small and large spot giving the same amount of excitation of the principal cell. In fact, Hubel and Wiesel [27] used this procedure in combination with extracellular recordings to propose that the increased peripheral suppression at the dLGN level results from a local inhibitory process. For the illustrated cell, this same amount of excitation was obtained with stimulus spots of $0.2^{\circ}$ and $1.8^{\circ}$, which both produced EPSP counts slightly above $60 \%$ of the peak activity. The larger of these spots evoked considerably more feedforward inhibition, however, which is easily seen from the sample records to the right.

A close scrutiny of many records at high magnification revealed that this difference was partly due to an increased number of nonlocked feedforward IPSPs, i.e. IPSPs without a preceding unitary EPSP. Indeed, twofold increase of nonlocked inhibition was observed with stimulus spot change from $0.2^{\circ}$ to $4.8^{\circ}$ (Fig. 8 , diagram to the left; $n=$ $10 ; t$-test, $p>0.01)$. The inhibitory responses in two of the traces to the right started with such nonlocked IPSPs (small arrows).These feedforward IPSPs were obviously evoked by activity in other off-centre ganglion cells than that providing excitation to the recorded principal cell. The responsible cells apparently had their receptive fields slightly displaced with respect to the excitatory field centre. Note that the curve for inhibition is below that for excitation up to a diameter of $0.9^{\circ}$ and above at larger stimulus diameters. Although the weight of the excitation and inhibition are not quite comparable, the shift of the curves illustrates that excitation dominates for smaller stimuli and inhibition for larger. In addition, for the other studied cells, including the Y cells, the diameter of the summation area for the feedforward inhibition was about twice as large as that of the excitatory centre.

\section{Basic pattern of recurrent inhibition}

As already described, slow presumed recurrent IPSPs were regularly evoked in the principal cells by centre stimuli of the opposite type to their excitatory input (Figs. 3, 4 and 5). Such IPSPs were also elicited by on and off stimulation in the surround of the principal cell receptive field. For many cells, there was also a late IPSP component in the excitatory phase of centre stimulation which was not accounted for by summation of feedforward IPSPs (Fig. 3). The underlying IPSP component had a slow rising phase with an overall latency similar to that of recurrent IPSP in the opposite phase of stimulation. These patterns are consistent with the 

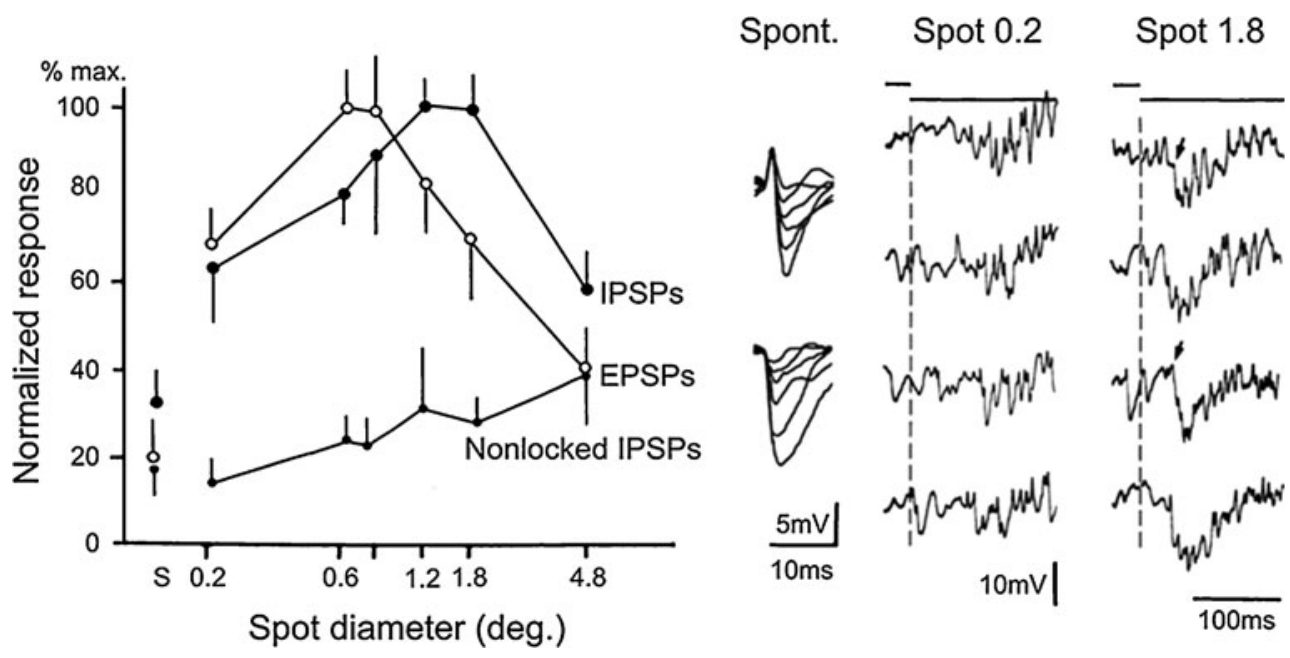

Fig. 8 Area response plot for EPSPs and feedforward IPSPs in an X off-centre principal cell. The diagram shows the mean number of unitary EPSPs and feedforward IPSPs evoked at light off by centred spot stimuli of different diameters. The cell received a single unitary EPSP from a ganglion cell in the contralateral eye, eccentricity of receptive field was $16^{\circ}$. The PSPs were counted during the first $100 \mathrm{~ms}$ after stimulus onset in a number of individual traces (with the IPSPs multiplied by a size factor of 1 to 3 ) and normalised with respect to the largest response (13.8 and 25.4/100 ms for the EPSP and IPSP). Vertical bars represent $95 \%$ c.i. The spontaneous rates are

known convergence of excitation of individual perigeniculate neurons as discussed above.

Threshold recurrent IPSPs required a higher stimulus intensity or summation from a somewhat larger stimulus area than feedforward IPSPs. For suboptimal stimuli, the latency of the recurrent IPSPs was also much longer than for the feedforward centre response, especially in X cells. We did not try to quantify these differences since they are mainly anaesthesia-dependent. Perigeniculate cells, especially those of $\mathrm{X}$ type, have a sluggish response in barbiturate anaesthetised animals [4]. Thus, the long latency of the recurrent IPSPs resulted from our experimental procedure and does not reflect the normal operation of the recurrent pathway during active vision. The effect was convenient for the present analysis, however, since it simplified the differentiation between visually evoked feedforward and recurrent IPSPs.

For more optimal visual stimuli, the latency difference between recurrent and feedforward IPSPs became negligible. The recurrent IPSPs had also similar latencies in onand off-centre cells (not illustrated), whether evoked from the receptive field centre or its surround or by light on or off stimuli (supplement; Fig. S4). This similarity is interesting since it implies that the recurrent IPSPs originated from centre stimulation of both on- and offcentre principal cells. Direct proof for the involvement of centre responses was obtained by stimulation with annuli. In such cases, the recurrent IPSPs always preceded the EPSPs elicited by surround activation of the ganglion cells indicated to the left (s). In the middle are superimposed traces of locked and nonlocked IPSPs of different amplitudes. The responses were sampled during a period of spontaneous activity and each trace is the average of five to six responses of comparable amplitude. Sample records to the right were obtained with a spots of $0.2^{\circ}$ and $1.8^{\circ}$, giving the same rate of activity of the excitatory retinal ganglion cell. Note the stronger feedforward inhibition evoked by the larger spot. Arrows point to a few large nonlocked IPSPs. Same cell as in Fig. 4. See text for further details

(supplement; Figs. S2 and S3). These findings are in keeping with previous observations from perigeniculate cells $[4,70]$.

\section{Recurrent inhibitory receptive fields}

\section{Recurrent receptive field profiles}

Recurrent inhibitory response profiles were determined in seven $\mathrm{X}$ and seven $\mathrm{Y}$ cells (half the sample was on-centre cells, two $\mathrm{X}$ cells were of the lagged type). A typical example for an X off-centre cell is shown in Fig. 9. EPSPs and recurrent IPSPs were evoked, as before, by small light spots placed in different positions along an axis through the excitatory receptive field centre. For this cell, the diameter of the EPSP centre at $1 / e$ peak amplitude was $0.6^{\circ}$. The recurrent IPSPs were quantified by averaging (for details, see legends) and are plotted separately for light on and off stimuli. The recurrent inhibition in the light on phase was clearly strongest from the receptive field centre. Its effective region extended well beyond the borders of the EPSP field. A wide recurrent profile was obtained also in the off phase of stimulation. The diameters of the different regions at $1 / e$ of the peak values were 1.2 and $1.4^{\circ}$ for the recurrent inhibitory fields, about twice for the excitatory field.

Centre stimulation also evoked the strongest recurrent inhibition in the other cells. The diameters of the recurrent field profiles were typically larger than those of feedforward 


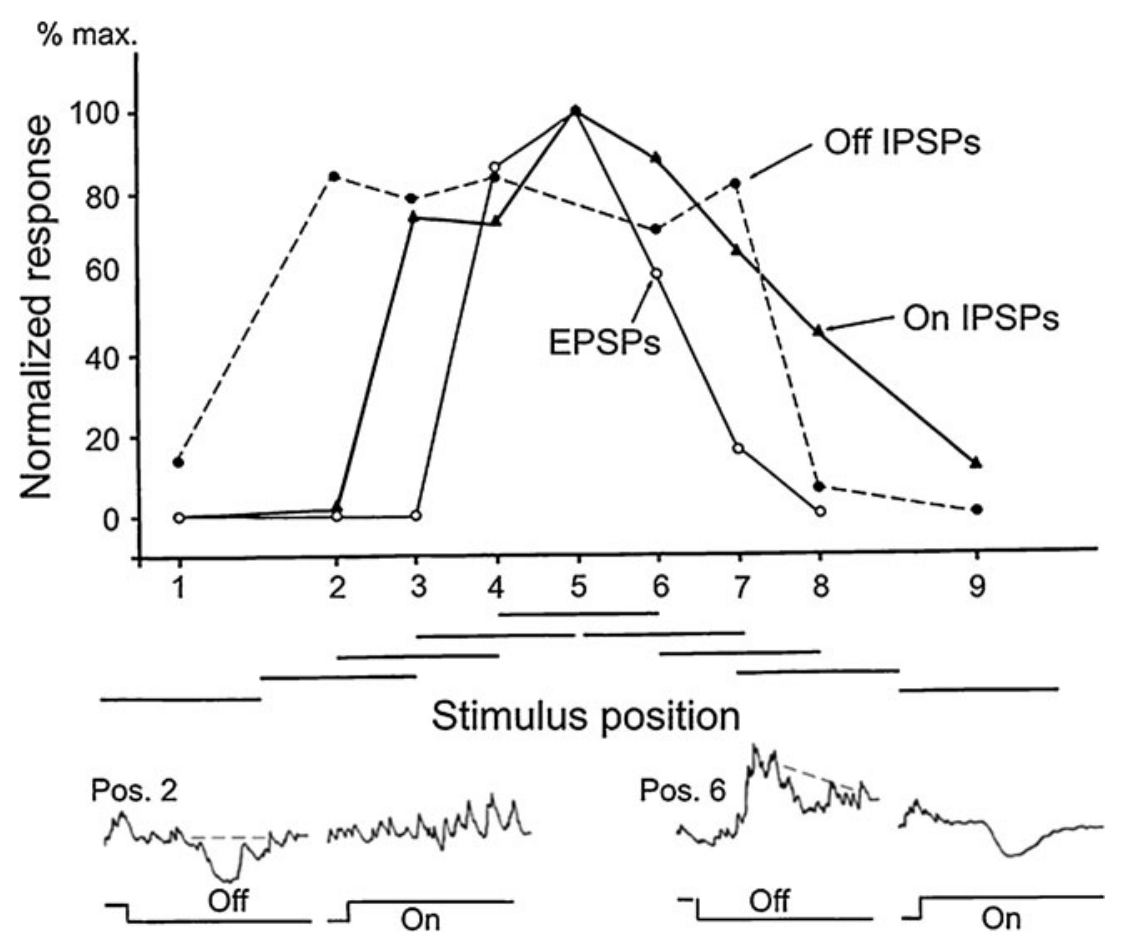

Fig. 9 Receptive field profile for recurrent IPSPs in an X off-centre principal cell. The PSPs were evoked by spot stimuli along an axis through the middle of the excitatory centre as indicated below the diagram. The cell received excitation from two retinal ganglion cells in the contralateral eye, eccentricity was $5^{\circ}$. The EPSP profile was determined by unitary counts as before and the recurrent IPSP profiles by integration of the area of averaged inhibitory responses. The latter measurements were restricted to a $60 \mathrm{~ms}$ period around the peak of the recurrent IPSP and normalised with respect to the largest response in the light on phase, when the recurrent IPSPs were uncontaminated by EPSPs. Separate plots are shown for responses evoked at light on and

IPSPs. Compared to the EPSP fields, the recurrent field diameters were 1.5 to three times larger, with no obvious difference between $\mathrm{X}$ and $\mathrm{Y}$ cells. These figures should be taken with some caution since the recurrent responses were very variable from trial to trial in our anaesthetised preparation, especially for stimuli in the marginal zone. The variability was particularly pronounced during periods of spindles in the ECoG when spontaneous recurrent IPSPs interfered with the visually evoked IPSPs. In several cells, the recurrent inhibitory fields were asymmetrical and different for on and off stimuli (Fig. 9, positions 2 and 8). In some parts of the receptive field, light on stimuli gave stronger effects than light off, in other parts the opposite could be true. We found no rules for this asymmetry. It presumably reflects an uneven, limited convergence of excitation from on- and off-centre principal cells onto individual perigeniculate neurons.

\section{Recurrent area-response functions}

The summation field of the recurrent inhibitory pathway was studied in four $\mathrm{X}$ and three $\mathrm{Y}$ cells, including both on- off with sample responses from positions 2 and 6 below. The baseline used to estimate the recurrent IPSP in the off mode is indicated by a dotted line. In the off phase, the recurrent IPSPs was measured against a background of summed EPSPs, since we were unable to depolarise this cell sufficiently to completely suppress its excitatory input. To estimate the inhibition, the outline of the EPSP response was extrapolated from records obtained with the cell hyperpolarised to the IPSP reversal level. Even with this correction procedure, the amplitudes of the recurrent IPSPs at light off in the receptive field centre were presumably underestimated. Stimulus Spot $0.4^{\circ}$; response duration $200 \mathrm{~ms}$. See text for further details

and off-centre cells. The change in recurrent inhibition evoked by spots of different sizes is shown in Fig. 10 with averaged recordings from an X off-centre principal cell. In this and other off-centre cells, the recurrent IPSPs were most easily seen in the on phase of stimulation, when there were no feedforward IPSPs. The inhibition increased up to a spot size of $1.9^{\circ}$, i.e. about 2.7 times the diameter of the excitatory receptive field centre.

Recurrent IPSPs of about the same amplitudes also occurred in the off phase of stimulation, but here, they were preceded by feedforward IPSPs forming the early part of the response. (Note that the fast rise time of unitary feedforward IPSPs is smoothed by the averaging procedure). The recurrent contribution in this phase appeared as a second inhibitory component (arrows, Spot 3) with about the same latency as the recurrent IPSP in the on phase of stimulation.

The most interesting observation, with respect to the recurrent inhibition, occurred with wide field stimuli. Such stimuli completely failed to evoke any recurrent inhibition in X cells. This failure was apparent both in the off- and on- 

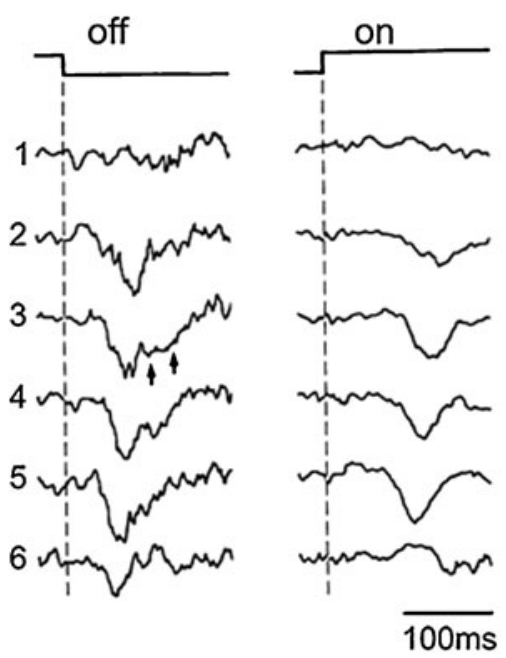

Fig. 10 Recurrent IPSPs evoked in an X off-centre principal cell by stimulus spots of different diameters. The size of the different stimuli in relation to the receptive field centre (dotted) are shown to the right and averages of the corresponding off and on responses to the left. Only recurrent IPSPs were evoked in the on mode of stimulation while the off stimuli evoked both short latency feedforward IPSPs and a later recurrent IPSP component (arrows in trace 3). The fast rise time

phase of stimulation with the largest spot (Fig. 10, Spot 6). At the expected latency for the recurrent IPSPs, there were no inhibitory responses, only small depolarisations representing disinhibition of the principal cell. Both the lack of recurrent inhibition and the disinhibition can be ascribed to the fact that X principal cells stop to fire spikes in response to wide field visual stimulation. Note that the feedforward inhibitory pathway was still operative as revealed by the early IPSP in the off response and the late hyperpolarisation in the on response. The latter was due to feedforward IPSPs evoked by surround activation of the off-centre retinal ganglion cell. Similar effects of wide field stimulation were found for all $11 \mathrm{X}$ cells tested with wide field stimuli. It follows from this kind of observation that the recurrent inhibitory pathway cannot be the main source of enhanced lateral inhibition of X principal cells, at least not for large stimuli. This finding makes it also unlikely that the slow IPSPs, inferred by us to represent recurrent IPSPs, included a substantial component of slow IPSPs generated locally at synaptic triads by intrageniculate interneurones, whether induced by dendritic calcium spikes [1] or activation of dendritic metabotropic glutamate receptors [14]. Both effects would be expected to be enhanced rather than suppressed by massive visual stimulation. Note that X-type intrageniculate interneurones maintain a substantial response to diffuse illumination (just like retinal ganglion cells and in contrast to X-type principal cells; [41]).

The situation might be different for $\mathrm{Y}$ cells. All tested $\mathrm{Y}$ principal cells (including nine additional cells with incomplete area response plots) displayed clear recurrent IPSPs in

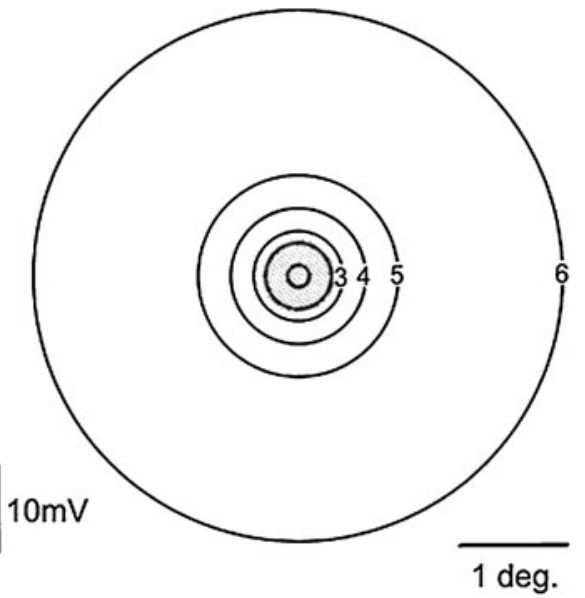

of the feedforward IPSPs is smeared by the averaging process. Note that the recurrent IPSP is replaced by a depolarising (disinhibitory) potential with the largest spot of stimulation (6). The late hyperpolarisation in the on trace was due to feedforward IPSPs paired with EPSPs from surround activation of the input retinal ganglion cell. Same cell as in Fig. 8

responses to wide field stimuli. Most Y principal cells also respond to such stimuli with a short burst of spikes both at light on and off. For the three Y cells, it was only feasible to determine the width of the recurrent inhibitory field using stimuli of the opposite phase to the centre excitation. In the latter phase of stimulation, it was impossible to quantify the recurrent IPSPs due to temporal overlap with feedforward IPSPs (supplement; Fig. S2). The recurrent summation area was considerably larger than that of feedforward inhibition and exceeded the diameter of the EPSP summation area at least three to four times. The inhibition decreased in amplitude with larger stimuli, but about half its peak amplitude remained with wide field stimuli.

\section{Discussion}

The present results demonstrate that the feedforward and recurrent inhibitory pathways of the dLGN carry different information and thus may subserve different functions. While the recurrent pathway combines information from the on- and off-centre systems, the feedforward pathway is type-specific, with the inhibition exclusively originating from the same type of retinal ganglion cells as the excitation. The receptive fields of both types of inhibition are bell-shaped and aligned with the excitatory receptive field. The diameter of the feedforward inhibitory field is about twice that for excitation while the recurrent inhibitory field is about two to four times larger. The structural 
organisation of the inhibitory fields is the same for $\mathrm{X}$ and $\mathrm{Y}$ principal cells, extending our previous observation that the inhibitory circuits of $\mathrm{X}$ and $\mathrm{Y}$ principal cells are similar although functionally segregated [34].

\section{Inhibitory mechanisms}

The strength of our observations is that visually evoked IPSPs were observed directly by intracellular recordings from dLGN principal cells. By polarising the cells, it was easy to differentiate between true postsynaptic inhibition and decreased excitation (disfacilitation), a distinction rarely made in the visual literature. From the shape and latency of the inhibitory potentials, it was also possible to differentiate between effects mediated by the feedforward and recurrent inhibitory pathways. The rationale behind this distinction is elaborated upon in the Results and will not be considered further.

There is a small possibility that some of the visually evoked IPSPs observed in our experiment would reflect the interneuronal activity evoked by the excitatory feedback loop via layer six pyramidal cells in the primary visual cortex [6]. Such activity would remain separated according to our criteria and contribute separately to the described feedforward and recurrent IPSP fields. We think, however, that such additional inputs are negligible in shaping the inhibitory fields as described here. First, layer 6 cells are virtually unresponsive to small spot stimuli as used here, especially in pentobarbital anaesthesia [36]. Secondly, the perigeniculate cells would inhibit other perigeniculate cells and feedforward interneurons shortly after their initial response $[6,71]$. Thirdly, even in the nonanaesthetised preparation, the cortical input was shown to be only modulatory to the spontaneous activity: increasing it for principal cells and decreasing for perigeniculate cells [62].

Only postsynaptic inhibitory effects were revealed by our recordings. Any presynaptic inhibition would have been undetected. At present, there is little evidence for specific presynaptic inhibition in the dLGN [51], although several transmitter substances have been found to modulate EPSP amplitudes in vitro [12]. Slow, long-latency IPSPs of GABA-B type $[16,55]$ were not observed in our responses whether evoked by electrical or visual stimulation. This negative result was probably due to a pronounced frequency depression of GABA-B IPSPs [55] caused by the high spontaneous activity of geniculate interneurons in vivo. It emphasises that known inhibitory effects on visual responses of dLGN principal cells is removed by GABAA antagonists $[8,50,61]$.

The feedforward inhibitory circuit of principal cells

The dLGN inhibitory circuitry, as it emerges from the present study, is shown schematically for an on-centre cell in Fig. 11. The circuitry would be essentially the same for the other cell types. A typical principal cell receives excitation from one to three neighbouring retinal ganglion cells with partly overlapping receptive fields $[41,46]$. Half the $\mathrm{X}$ cells and about a third of the $\mathrm{Y}$ cells are excited by only one retinal ganglion cell (unpublished observations). The feedforward inhibition also involves a small number of intrageniculate interneurons (4-6, as judged from the present results). For the $\mathrm{X}$ pathway, these interneurons may receive most, if not all, their excitatory input from retinal ganglion cells at synaptic triads in dLGN glomeruli. Here, they also form contacts with the same principal cell as their input optic nerve fiber [20]. These triads are most likely the anatomical substrate for the locked feedforward IPSPs that were such a characteristic feature of $X$ cells in the present study (see also [10]). Only a small fraction of these tightly coupled IPSPs would be accounted for by correlated firing of neighbouring retinal ganglion cells [40]. Thus, the physiology finding that principal cells receive feedforward inhibition from its excitatory retinal ganglion cell is well explained by the anatomy of synaptic triads.

The tight coupling to the excitatory input explains why the feedforward inhibition is strongest in the receptive field centre. Since the inhibitory field is about twice as large as the excitatory centre, also the nearest neighbours in the retinal mosaic would contribute to the inhibition. Only a small number of cells would be engaged as judged from the ganglion cell packing in the retina. Here, $\mathrm{X}$ cells of the same receptive field type are arranged in a somewhat noisy hexagonal pattern with the dendritic fields displaced by about a centre radius $[41,46]$. Therefore, the feedforward

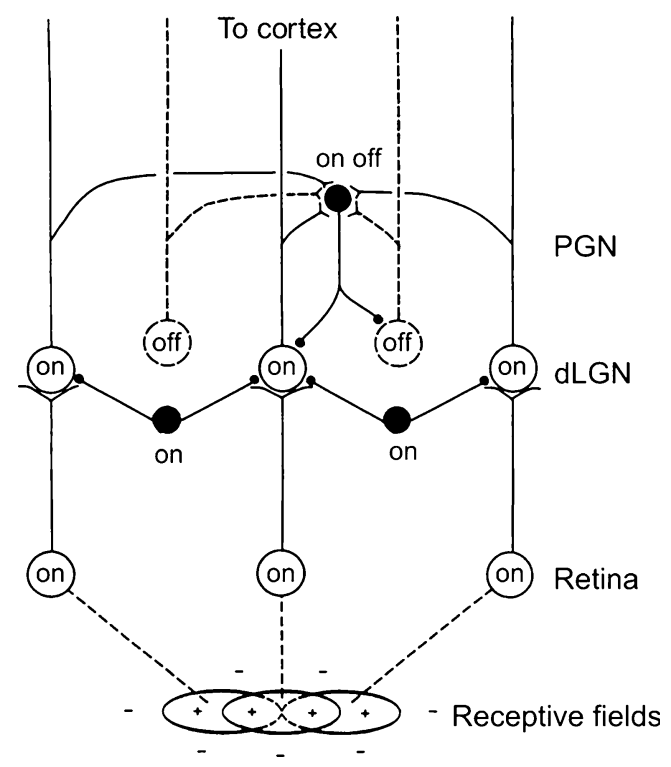

Fig. 11 Schematic diagram of feedforward and recurrent inhibitory circuits of an on-centre principal cell in the dLGN. Open and filled circles represent excitatory and inhibitory cells, respectively. See text for further details 
inhibitory field could be formed by as little as seven retinal ganglion cells. Most likely, these neighbouring retinal ganglion cells would converge onto common intrageniculate interneurons, which in turn would distribute their inhibition to several principal cells with spatially overlapping but separate excitatory inputs. Again, most of these connections would occur at triads, thereby forming the anatomical substrate for nonlocked feedforward IPSPs. Unlocked IPSPs could also be mediated by locally ramifying axons from the interneurons [59, 71].

This scheme is consistent with the finding that only 20$25 \%$ of the neurons in the cat's dLGN are GABAergic interneurons [64]. It also agrees with the variation in amplitude of locked and nonlocked feedforward IPSPs, whether evoked by visual stimulation or by spontaneous ganglion cell activity. We have assumed that this variability is caused by a variation in the number of activated intrageniculate interneurons, each discrete step representing the inhibitory input of one spike in one interneuron. The number of discrete steps may thus give an estimate of the number of converging interneurons (4-6). This interpretation is supported by the finding of a similar stepwise gradation of feedforward IPSPs evoked by electrical stimulation of the optic nerve [34]. In this case, there was a threshold difference between steps proving that axons of different retinal ganglion cells contributed excitation to the pool of interneurons.

The alternative interpretation that the stepwise change in feedforward IPSPs represent independent local release from single triads [14, 49] seems less likely. Intrageniculate interneurons of both $\mathrm{X}$ and $\mathrm{Y}$ types fire some spikes in response to excitation from ganglion cells and corticogeniculate neurons $[33,41,43,45,71]$. The delay and time course of the feedforward IPSPs in principal cells and the occurrence of spatial facilitation at interneuronal level indicates that the IPSPs are spike evoked [33]. Further, principal cells receive excitation from a single retinal ganglion cell at a large number of synaptic sites [24]. Why should the feedforward inhibitory input at these sites operate independently? A somewhat disappointing implication is that the synaptic triads of the dLGN may be trivial from a functional point of view. The structure may simply have emerged as the most economical way of constructing a type specific feedforward inhibitory network with a limited number of interneurons.

The recurrent inhibitory circuit of principal cells

Recurrent IPSPs were evoked by light on and off stimuli in all parts of the receptive fields, similarly for $\mathrm{X}$ and $\mathrm{Y}$ cells. The latency of these inhibitory responses was the same and consistently shorter than for EPSPs evoked by surround stimulation of ganglion cells. It follows that the recurrent inhibitory effects were mainly due to centre stimulation of both on- and off-centre ganglion cells. This finding agrees with the observations that the excitation of individual perigeniculate neurons originates from both on- and offcentre principal cells with overlapping receptive fields $[4$, 70]. For clarity, the diagram in Fig. 11 is oversimplified with respect to the recurrent circuit. The mutual inhibitory connections between perigeniculate neurons or their projection to intrageniculate interneurons are not shown $[6$, 71], nor is the full spatial extent of their connections.

The convergence number for principal cells onto single perigeniculate cells is not known but might be as high as 20-40. This estimate comes from their binocular input from both on- and off-centre principal cells and response fields about twice the field centre of principal cells at the same eccentricity $[4,67]$. The number of perigeniculate neurons converging onto a single principal cell is neither known, but it may be about the same as for the feedforward pathway. Such a convergence would account for the bell-shaped recurrent inhibitory receptive fields about three to four times larger than the EPSP fields of the principal cells, as found here.

These considerations agree with the small number of perigeniculate neurons that supply recurrent inhibition to the entire dLGN. In fact, the connectivity seem to be at the margin for a complete coverage of the receptive fields. Thus, we frequently observed asymmetrical on and off inhibitory responses in parts of the recurrent inhibitory field. Such asymmetries may explain some of the orientation tuning observed for geniculate cells [61]. Whatever, the recurrent inhibitory fields of principal cells are much smaller than generally assumed for this pathway $[49,51]$ suggesting that it is inappropriate to refer to the recurrent inhibitory system in terms of "diffuse inhibition." Even if our measure is somewhat underestimated due to the low excitability of perigeniculate cells in barbiturate anaesthesia, the size of the inhibitory field agrees rather well with the termination arbor of perigeniculate axons in the dLGN [60]. Lateral spread of recurrent inhibition may also be limited by the mutual inhibitory connections of perigeniculate cells [29]. Such a mechanism could explain why "long-range inhibition" appears in the dLGN after acute local destruction of the retina [19].

Comparison with other studies

Several procedures have been used in the past to study the organisation and function of the dLGN inhibition: (1) comparison of the firing responses of input retinal ganglion cell and target dLGN cell to different visual stimuli $[27,31$, 37,58 , etc.]; (2) cross-correlation between impulse activity of two geniculate neurons [56], retinal and geniculate neurons $[39,41]$ or mutual recordings from dLGN and 
PGN cells [22]; (3) comparison of geniculate cell responses before and after iontophoretic blockade of GABA receptors by specific antagonist $[8,19,50,61]$; (4) quasi-intracellular or intracellular recordings of visually evoked responses $[44$, $52,53,63]$.

All but the latter studies have relied on indirect methods to identify inhibitory effects in the dLGN. This fact may explain why almost every conceivable model has been proposed to account for the increased peripheral antagonism of principal cells [27]. All models contain some components in common with the inhibitory circuitry as revealed here. For instance, Levick et al. [31] were correct with respect to the organisation of recurrent inhibitory pathway, and Singer et al. [53] in identifying "synergistic" inhibition from the receptive field centre. Likewise our scheme for feedforward inhibition is identical to that proposed by Mastronarde [39, 41] for lagged X cells, the difference being that we find a similar circuitry also for non-lagged $\mathrm{X}$ cells and for $\mathrm{Y}$ cells. The push-pull hypothesis proposed by Wang et al. [63] was based on an indirect procedure to estimate inhibition rather than direct observations of IPSP events. Our results suggest that their "pull" effect from the receptive centre was mainly due to disfacilitation, possibly primed by some recurrent inhibition. So the main merit of the present study is that the correct circuits could be sorted out among a list of proposed alternatives. In addition, we were able to show that the inhibitory fields were bell-shaped with the strongest effect in the excitatory field centre, as originally proposed for the surround mechanism of retinal ganglion cells by Rodieck and Stone [47].

\section{Functional considerations}

Although this study relied on visual stimulation, its main goal was to analyse the inhibitory circuits of the dLGN rather than their function in vision. Our intracellular recordings were essentially qualitative and quantitative differences may exist between the inhibition of $\mathrm{X}$ and $\mathrm{Y}$ cells or lagged and non-lagged cells. Such differences may affect their response characteristics even if their basic circuits are the same. The anaesthesia may also influence the relative importance of the feedforward and recurrent inhibitory systems in the control of principal cell activity, especially since the excitability of perigeniculate cells is much depressed in barbiturate anaesthesia [4, 42]. Finally, we used step-modulated light stimuli in order to obtain optimal time separation between feedforward and recurrent IPSPs. Such stimuli introduce artificial transients in the excitatory and inhibitory inputs to the principal cells [25].

Some functional implications can be derived from our results, however. Both the feedforward and recurrent inhibitory fields were larger than the excitatory field of the principal cells so both mechanisms could conceivably contribute to the increased peripheral antagonism of the centre response [27]. For X cells, however, it is evident that only the feedforward inhibitory pathway was operative with wide field stimulation. Such stimuli produced enough feedforward inhibition to keep the principal cells below their firing thresholds and, accordingly, the perigeniculate neurons without excitation. So the recurrent inhibitory system could not account for the enhanced surround inhibition in this situation.

The feedforward system may have the same role for $\mathrm{Y}$ principal cells although they typically respond with a brief burst of spikes to wide field stimuli and receive short latency recurrent IPSP to such stimuli. However, the surround inhibition of their centre response is less effective than in $X$ cells [8], which is contrary to what would be expected if additional inhibition was provided by the recurrent pathway. The role of the feedforward inhibitory system may thus be the same in $\mathrm{X}$ and $\mathrm{Y}$ principal cells, namely, to improve the detection of contrast borders [38] or, in other terms, to sharpen their spatial filtering in the low frequency range $[8,37,38]$.

Why is such filtering performed in two stages, first at the retinal level and then in the dLGN? The explanation may be that biological restrains preclude the construction of filtering circuits without superimposition of excitatory and inhibitory fields. Such a superimposition inevitable involves a loss in absolute sensitivity of the excitatory centre mechanism. This would be true even if the majority of the feedforward IPSPs are time-locked to EPSPs with their peak amplitude well after the EPSP peak, as found here. By influencing the firing probability for subsequent EPSPs locked IPSPs may still have a substantial effect on the overall signal transfer through the dLGN [10]. This sensitivity loss may be partly compensated for by an external inhibitory control of the intrageniculate interneurons. Some brain stem neurons with selective projection to the main dLGN layers may have such a role $[2,5]$. A sensitivity increase at the expense of spatial resolution might be useful during vision at very low levels of illumination $[11,37,65]$ or at low contrast as may happen in deep fog.

What is then the role of the recurrent inhibitory system? We have already proposed that it is a component in a variable gain regulator for the transmission of visual signals through the dLGN [6], the other component being the recurrent excitatory pathway through corticogeniculate cells in layer 6 of the primary visual cortex $[21,23,35,62]$. These two complimentary recurrent pathways are suggested to be the executive links in an attention system composed of a neuronal attenuator (inhibition) and an amplifier (excitation). Central to this hypothesis is the idea that both recurrent systems can be independently controlled by 
extravisual neuronal systems $[5,9,17,36,54]$. The hypothesis is a concretisation of earlier ideas about the function of the dLGN $[26,51]$. It is basically similar to the searchlight hypothesis of Crick [15], with the important difference that the corticogeniculate pathway, rather than the perigeniculate, is given the role of a positive amplifier. Our recent studies on behaving animals [66-69] are in line with the attentional hypothesis and give an experimental support to the proposed function of the recurrent system.

Acknowledgements The present study was supported by the Swedish Medical Research Council (Project No. 04767) and the Polish Ministry of Science and Higher Education (Project No. COST/ 127/2007).

\section{Conflicts of interest None}

Open Access This article is distributed under the terms of the Creative Commons Attribution Noncommercial License which permits any noncommercial use, distribution, and reproduction in any medium, provided the original author(s) and source are credited.

\section{References}

1. Acuna-Goycolea C, Brenowitz SD, Regehr WG (2008) Active dendritic conductances dynamically regulate GABA release from thalamic interneurons. Neuron 57:420-431

2. Ahlsén G (1984) Brain stem neurons with differential projection to functional subregions of the dorsal lateral geniculate complex in the cat. Neuroscience 12:817-838

3. Ahlsén G, Lindström S (1982) Excitation of perigeniculate neurons via axon collaterals of principal cells. Brain Res 236:477-481

4. Ahlsén G, Lindström S, Lo F-S (1983) Excitation of perigeniculate neurones from $\mathrm{X}$ and $\mathrm{Y}$ principal cells in the lateral geniculate nucleus of the cat. Acta Physiol Scand 118:445-448

5. Ahlsén G, Lindström S, Lo F-S (1984) Inhibition from the brain stem of inhibitory interneurones of the cat's dorsal lateral geniculate nucleus. J Physiol 347:593-609

6. Ahlsén G, Lindström S, Lo F-S (1985) Interaction between inhibitory pathways to principal cells in the lateral geniculate nucleus of the cat. Exp Brain Res 58:134-143

7. Allitto HJ, Usrey WM (2008) Origin and dynamics of extraclassical suppression in the lateral geniculate nucleus of the macaque monkey. Neuron 75:135-146

8. Berardi N, Morrone MC (1984) The role of $\gamma$-aminobutyric acid mediated inhibition in the response properties of cat lateral geniculate nucleus neurones. J Physiol 357:505-523

9. Bickford ME, Günlük AE, Van Horn SC, Sherman SM (1994) GABAergic projection from the basal forebrain to the visual sector of the thalamic reticular nucleus in the cat. J Comp Neurol 348:481-510

10. Blitz DM, Regehr WG (2005) Timing and specificity of feedforward inhibition within the LGN. Neuron 45:917-928

11. Bonin V, Mante V, Carandini M (2005) The suppressive field of neurons in lateral geniculate nucleus. J Neurosci 25:10844-10856

12. Chen C, Regehr WG (2003) Presynaptic modulation of the retinogeniculate synapse. J Neurosci 23:3130-3135

13. Cleland BG, Harding TH, Tulunay-Keesey U (1979) Visual resolution and receptive field size: examination of two kinds of cat retinal ganglion cell. Science 205:1015-1017
14. Cox CL, Zhou Q, Sherman SM (1998) Glutamate locally activates dendritic outputs of thalamic interneurons. Nature 394:478-482

15. Crick F (1984) Function of thalamic reticular complex: the searchlight hypothesis. Proc Natl Acad Sci USA 81:4586-4590

16. Crunelli V, Haby M, Jassik-Gerschenfeld D, Leresche N, Pirchio $\mathrm{M}$ (1988) $\mathrm{Cl}^{-}$and $\mathrm{K}^{+}$- dependent inhibitory postsynaptic potentials evoked by interneurones of the rat lateral geniculate nucleus. J Physiol 399:153-176

17. De Lima AD, Singer W (1987) The brainstem projection to the lateral geniculate nucleus in the cat: identification of cholinergic and monaminergic elements. J Comp Neurol 259:92-121

18. Dubin MW, Cleland BG (1977) Organisation of visual inputs to interneurons of lateral geniculate nucleus of the cat. J Neurophysiol 40:410-427

19. Eysel UT, Pape H-C, van Schayck R (1986) Excitatory and differential disinhibitory actions of acetylcholine in the lateral geniculate nucleus of the cat. J Physiol (London) 370:233-254

20. Famiglietti EV, Peters A (1972) The synaptic glomerulus and the intrinsic neuron in the dorsal lateral geniculate nucleus of the cat. J Comp Neurol 144:285-334

21. Ferster D, Lindström S (1985) Synaptic excitation of neurones in area 17 of the cat by intracortical axon collaterals of corticogeniculate cells. J Physiol 376:233-252

22. Funke K, Eysel UT (1998) Inverse correlation of firing patterns of single topographically matched perigeniculate neurons and cat dorsal lateral geniculate relay cells. Vis Neurosci 15:711-729

23. Granseth B, Lindström S (2003) Unitary EPSCs of corticogeniculate fibers in the rat dorsal lateral geniculate nucleus in vitro. J Neurophysiol 89:2952-2960

24. Hamos JE, Van Horn SC, Raczkowski D, Sherman SM (1987) Synaptic circuits involving an individual retinogeniculate axon in the cat. J Comp Neurol 259:165-192

25. Heggelund P, Karlsen HE, Flugsrud G, Nordtug T (1989) Response to rates of luminance change of sustained and transient cells in the cat lateral geniculate nucleus and optic tract. Exp Brain Res 74:116-130

26. Hernandez-Peon R (1966) Physiological mechanisms in attention. In: Russel RW (ed) Frontiers in physiological psychology. Academic, New York

27. Hubel DH, Wiesel TN (1961) Integrative action in the cat's lateral geniculate body. J Physiol 155:385-398

28. Humphrey AL, Weller RE (1988) Structural correlates of functionally distinct X-cells in the lateral geniculate nucleus of the cat. J Comp Neurol 268:448-468

29. Huntsman MM, Porcello DM, Homanics GE, DeLorey TM, Huguenard JR (1999) Reciprocal inhibitory connections and network synchrony in the mammalian thalamus. Science 283:541-543

30. Lesica NA, Weng C, Jin J, Yeh C-I, Alonso J-M, Stanley GB (2006) Dynamic encoding of natural luminance sequences by LGN bursts. PLoS Biol 4:e209

31. Levick WA, Cleland BG, Dubin MW (1972) Lateral geniculate neurons of the cat: retinal inputs and physiology. Invest Ophtalmol 11:302-311

32. Lindström S (1982) Synaptic organisation of inhibitory pathways to principal cells in the lateral geniculate nucleus of the cat. Brain Res 234:447-453

33. Lindström S (1983) Interneurones in the lateral geniculate nucleus with monosynaptic excitation from retinal ganglion cells. Acta Physiol Scand 119:101-103

34. Lindström S, Wróbel A (1990) Private inhibitory systems for the $\mathrm{X}$ and $\mathrm{Y}$ pathways in the dorsal lateral geniculate nucleus of the cat. J Physiol 429:259-280

35. Lindström S, Wróbel A (1990) Frequency dependent corticofugal excitation of principal cells in the cat's dorsal lateral geniculate nucleus. Exp Brain Res 79:313-318 
36. Livingstone MS, Hubel DH (1981) Effects of sleep and arousal on the processing of visual information in the cat. Nature 291:554-561

37. Maffei L, Fiorentini A (1972) Retinogeniculate convergence and analysis of contrast. J Neurophysiol 35:65-72

38. Marr D, Hildreth E (1980) Theory of edge detection. Proc R Soc Lond B 207:187-217

39. Mastronarde DN (1987) Two classes of single-input X-cells in cat lateral geniculate nucleus: II. Retinal inputs and the generation of receptive-field properties. J Neurophysiol 57:381-413

40. Mastronarde DN (1989) Correlated firing of retinal ganglion cells. TINS 12:75-80

41. Mastronarde DN (1992) Nonlagged relay cells and interneurons in the cat lateral geniculate nucleus: receptive-field properties and retinal inputs. Vis Neurosci 8:407-441

42. McCormick DA, Bal T (1997) Sleep and arousal: thalamocortical mechanisms. Ann Rev Neurosci 20:185-215

43. McCormick DA, Pape H-C (1988) Acetylocholine inhibits identified interneurons in the cat lateral geniculate nucleus. Nature 334:246-248

44. McIlwain JT, Creutzfeldt O (1967) Microelectrode study of synaptic excitation and inhibition in the lateral geniculate nucleus of the cat. J Neurophysiol 30:1-21

45. Pape HC, McCormick DA (1995) Electrophysiological and pharmacological properties of interneurons in the cat dorsal lateral geniculate nucleus. Neuroscience 68:1105-1125

46. Peichl L, Wässle H (1979) Size, scatter and coverage of ganglion cell receptive field centres in the cat retina. J Physiol 291:117-141

47. Rodieck RW, Stone J (1965) Analysis of receptive fields of cat retinal ganglion cells. J Neurophysiol 28:833-849

48. Sherman SM, Guillery RW (1996) Functional organisation of thalamocortical relays. J Neurophysiol 76:1367-1395

49. Sherman SM, Koch C (1986) The control of retinogeniculate transmission in the mammalian lateral geniculate nucleus. Exp Brain Res 63:1-20

50. Sillito AM, Kemp JA (1983) The influence of GABAergic inhibitory processes on the receptive field structure of $\mathrm{X}$ and $\mathrm{Y}$ cells in cat dorsal lateral geniculate nucleus (dLGN). Brain Res 277:63-77

51. Singer W (1977) Control of thalamic transmission by corticofugal and ascending reticular pathway in the visual system. Physiol Rev $57: 386-420$

52. Singer W, Creutzfeldt OD (1970) Reciprocal lateral inhibition of on- and off-centre neurons in the lateral geniculate body of the cat. Exp Brain Res 10:311-330

53. Singer W, Pöppel E, Creutzfeldt O (1972) Inhibitory interaction in the cat's lateral geniculate nucleus. Exp Brain Res 14:210-226

54. Smith Y, Pare D, Deschenes M, Parent A, Steriade M (1988) Cholinergic and noncholinergic projection from the upper brainstem core to the visual thalamus in the cat. Exp Brain Res 70:166-180

55. Soltesz I, Lightowler S, Leresche N, Crunelli V (1989) On the properties and origin of the GABA-B inhibitory postsynaptic potential recorded in morphologically identified projection cells of the cat dorsal lateral geniculate nucleus. Neuroscience 33:23-33

56. Stevens JK, Gerstein GL (1976) Spatiotemporal organisation of cat lateral geniculate receptive fields. J Neurophysiol 39:213-238

57. Troy JB (1983) Spatial contrast sensitivities of X and Y type neurones in the cat's dorsal lateral geniculate nucleus. J Physiol 344:399-417

58. Uglesich R, Casti A, Hayot F, Kaplan E (2009) Stimulus size dependence of information transfer from retina to thalamus. Front Systems Neurosci 3, Article 10

59. Uhlrich DJ, Cucchiaro JB (1992) GABAergic circuits in the lateral geniculate nucleus of the cat. Progr Brain Res 90:171-192

60. Uhlrich DJ, Cucchiaro JB, Humphrey AL, Sherman SM (1991) Morphology and axonal projection patterns of individual neurons in the cat perigeniculate nucleus. J Neurophysiol 65:1528-1541

61. Vidyasagar TR (1984) Contribution of inhibitory mechanisms to the orientation sensitivity of cat dLGN neurones. Exp Brain Res 55:192-195

62. Waleszczyk WJ, Bekisz M, Wróbel A (2005) Cortical modulation of neuronal activity in the cat's lateral geniculate and perigeniculate nuclei. Exp Neurol 196:54-72

63. Wang X, Wei Y, Vaingankar V, Wang Q, Koepsell K, Sommer FT, Hirsch JA (2007) Feedforward excitation and inhibition evoke dual modes of firing in the cat's visual thalamus during naturalistic viewing. Neuron 55:465-478

64. Weber AJ, Kalil RE (1983) The percentage of interneurons in the dorsal lateral geniculate nucleus of the cat and observations on several variables that affect the sensitivity of horseradish peroxidase as a retrograde marker. J Comp Neurol 220:336-346

65. Wróbel A (1981) Light level induced reorganization of cat's lateral geniculate nucleus receptive fields. Spatiotemporal study. Acta Neurobiol Exp (Wars) 41:447-466

66. Wróbel A (2000) Beta activity: a carrier for visual attention. Acta Neurobiol Exp Wars 60:247-260

67. Wróbel A, Bekisz M (1994) Visual classification of X and Y neurones in the perigeniculate nucleus of the cat. Exp Brain Res 101:307-313

68. Wróbel A, Bekisz M (2003) Attention-dependent coupling between beta activities recorded in the cat's thalamic and cortical representations of the central visual field. Europ J Neurosci 17:421-426

69. Wróbel A, Ghazaryan A, Bekisz M, Bogdan W, Kamiński J (2007) Two streams of attention dependent beta activity in the striate recipient zone of cat's lateral posterior - pulvinar complex. $\mathrm{J}$ Neurosci 27:2230-2240

70. Wróbel A, Tarnecki R (1984) Receptive fields of cat's non-relay lateral geniculate and perigeniculate neurons. Acta Neurobiol Exp Wars 44:289-299

71. Zhu JJ, Lo F-S (1999) Three GABA receptor mediated postsynaptic potentials in interneurons in the rat lateral geniculate nucleus. J Neurosci 19:5721-5730 